\title{
Análogos de reservatórios de rampa de água profunda: sistemas ricos em lama (unidade de Apiúna-SC) e em areia (Formação Punta Negra, Pré- Cordilheira Argentina)
}

\author{
Pedro Henrique Vieira de Luca ${ }^{1}$ \& Giorgio Basilici ${ }^{2}$
}

\begin{abstract}
Resumo Dois principais motivos justificam o estudo de afloramentos na geologia do petróleo. O primeiro, quase óbvio, é o estudo de sucessões expostas que, em subsuperfície, apresentam potencialidade para exploração de hidrocarbonetos. O segundo é a produção de modelos análogos de distribuição geométrica de reservatórios. Neste trabalho são considerados dois modelos de sistemas de água profunda derivados da análise de afloramentos: um sistema de rampa rico em lama e um sistema de rampa rico em arenitos. O primeiro modelo deriva do estudo da Unidade de Apiúna de idade pré-cambriana do estado de Santa Catarina. A Unidade de Apiúna é uma sucessão espessa $4.500 \mathrm{~m}$, constituída prevalentemente de argilitos laminados interrompidos por sistemas de canais e lençóis de areia, distribuídos em modo irregular. O segundo modelo deriva do estudo de um sistema de idade devoniana da Pré-Cordilheira Argentina, a Formação Punta Negra. Este modelo é caracterizado pela predominância de depósitos de arenito, desenvolvidos em grandes corpos lenticulares achatados não-confinados de lençóis de areia, cortados por corpos confinados de arenitos. Varias formas canalizadas com indicadores de paleocorrentes ao longo de $250 \mathrm{~km}$ indicam um sistema multi-aporte, tipo rampa. A reconstrução da arquitetura deposicional mostra dimensões, propriedades petrofísicas e conectividades melhores nos potenciais reservatórios de sistema de rampa rico em areia e um maior risco de exploração em sistema de rampa rico em pelito. Todavia, nos sistemas de rampa ricos em areia não há rochas selantes, ao contrario do que ocorre nos sistemas de rampa ricos em pelito.
\end{abstract}

Palavras-chave: elementos arquiteturais, reservatórios de hidrocarbonetos, sistemas deposicionais de água profunda, Unidade de Apiúna, Formação Punta Negra.

\begin{abstract}
Reservoir analogues of deepwater ramp: a mud-rich (Apiúna unit, Santa Catarina) and a sand-rich system (Punta Negra Formation, Argentine Precordillera). Two main reasons justify the use of outcrops in petroleum geology. The former, almost obvious, is related to the outcrop study in sedimentary successions with potential hydrocarbon exploration. The second is the production of models of geometric reservoirs distribution. In this work we consider two deepwater system models generated from outcrop analysis. A mud-rich deepwater ramp and a sand-rich deepwater ramp, represented, respectively by: i) Apiúna Unit, préCambrian, Santa Catarina State and ii) Punta Negra Formation, Devonian, Argentine Precordillera. The Apiúna Unit is $4,500 \mathrm{~m}$ thick mainly constituted by laminates mudstones crosscut by channel and sheet sand systems, irregularly distributed. The Punta Negra Formation is characterized by the predominance of sandy deposits, originated in long unconfined sand sheet bodies with a wedge geometry crosscut by confined sandstones. The presence of various channelized bedforms oriented approximately in the same direction, in an extensive area of $250 \mathrm{~km}$, suggests a multiple sedimentary input ramp system to this unit. The depositional architecture reconstruction shows that in sand-rich systems the dimension, petrophysical properties and connectivity of the sandstones construct better potential reservoirs. The reservoir quality and distribution in mud-rich ramp systems show more risks in oil exploration. However, differently than mud-rich systems, the sand-rich systems does not have sealing rocks.
\end{abstract}

Keywords: architectural elements, hydrocarbon reservoirs, deepwater systems, Apiúna Unit, Punta Negra Formation.

INTRODUÇÃO O sucesso na extração de hidrocarbonetos depende da caracterização dos corpos reservatórios. As principais dificuldades na compilação de modelos de reservatórios de alta confiabilidade estão relacionadas à complexidade interna e externa dos litossomas e de suas inter-relações com corpos adjacen- tes.

As técnicas empregadas na construção do modelo direto em subsuperfície, como sísmica, perfilagem e uso de testemunhos, fornecem dados pouco completos e com muitas incertezas, devidos à baixa resolução vertical dos métodos sísmicos e à limitada área de abran- 
gência dos dados de perfis e testemunhos de poços. De uma forma geral, informações como geometria, extensão e características internas dos corpos sedimentares são incompletas e de baixa precisão.

A utilização de modelos geológicos dos sistemas deposicionais confeccionados a partir do estudo de afloramentos de unidades análogas é uma ferramenta importante na tentativa de diminuir as incertezas inerentes ao processo de caracterização dos reservatórios.

Slatt (2000) argumenta que os afloramentos fazem uma ponte entre dados pontuais extraídos dos poços e as seções sísmicas 3D de larga escala. Kneller (1995) e Shanmugam (2000) ressaltam que a consideração dos processos deposicionais no estudo da arquitetura das rochas é uma premissa fundamental para construir modelos deposicionais plausíveis.

Os modelos geológicos de sistemas análogos permitem o reconhecimento de propriedades internas e externas importantes, como a identificação de heterogeneidades e de barreiras de permeabilidade e porosidade, nem sempre identificáveis em subsuperfície.

Os sistemas de água profunda têm se constitituído em um dos principais alvos da exploração de petróleo. Segundo Stow \& Mayall (2000) os depósitos turbidíticos e seus reservatórios permanecerão na vanguarda da exploração e produção de óleo e gás por, pelo menos, 25 anos. Entretanto, estes sistemas sedimentares podem conter um percentual maior que $80 \%$ de óleo móvel não-recuperável (Unrecovered Mobile Oil) (Tyler, 1998; Ambrose et al., 1991). Segundo Tyler \& Finley (1991) o maior motivo da dificuldade na recuperação dos hidrocarbonetos é o caráter limitado e inadequado dos estudos sobre a arquitetura geológica dos reservatórios e o controle que os elementos dessa arquitetura exercem sobre o fluxo de óleo durante a extração.

O objetivo principal deste trabalho é caracterizar a distribuição arquitetural de sistemas profundos de rampa submarina. Para isso utilizaram-se duas unidades litoestratigráficas antigas: a Unidade de Apiúna (UA) (Pré-Cambriano, Bacia do Itajaí), e a Formação Punta Negra (FPN) (Devoniano, Pré-Cordilheira Argentina). Estas duas unidades representam, respectivamente, sistemas ricos em lama e sistemas ricos em areia (sensu Reading \& Richards, 1994).

Este trabalho se baseia nos elementos arquiteturais, que constituem ferramenta prática e eficaz no estudo da geometria deposicional, especialmente para aplicação industrial. De fato, Stow \& Mayall (2000) afirmam que a pesquisa em sistemas profundos deve começar com a definição dos elementos arquiteturais, seus padrões de empilhamento, geometrias e atributos físicos.

\section{A UNIDADE DE APIÚNA}

Contexto Geológico A Unidade de Apiúna (UA) é uma unidade clástica de água profunda, espessa cerca de $4.500 \mathrm{~m}$, que é parte do preenchimento da Bacia do Itajaí, de idade pré-cambriana, localizada no estado de Santa Catarina (Fig. 1A). Esta bacia é interpretada como de antepaís, ligada à formação da estrutura orogenética Dom Feliciano (Rostirolla et al., 1999).

A sucessão estratigráfica desta bacia não possui ainda um claro modelo. Existem duas principais interpretações (Fig. 1B). (1) Segundo Rostirolla et al. (1999) a UA estaria colocada entre duas unidades de sedimentos areníticos e conglomeráticos, continentais e costeiros: uma, mais antiga, com proveniência da margem norte da bacia e uma outra, mais recente, com proveniência da margem sul da bacia. (2) Segundo Krebs et al. (1988) a UA é a unidade mais recente do preenchimento da Bacia do Itajaí, e estaria situada acima de depósitos conglomeráticos e areníticos de origem continental e costeira.

A UA é uma sucessão sedimentar gravitacional caracterizada por depósitos de granulometria fina. Basilici (2006) descreve as principais litofácies, os relativos mecanismos deposicionais e os elementos arquiteturais da porção inferior desta sucessão, que a interpreta como um sistema de rampa de água profunda rico em pelito e areia, segundo a classificação de Reading \& Richards (1994).

Neste trabalho é considerada a sucessão completa da UA e é apresentada uma amplificação e reinterpretação de trabalhos anteriores (Basilici \& Martins, 2004; Basilici, 2006).

Elementos Arquiteturais Este estudo é baseado na definição dos elementos arquiteturais ou elementos deposicionais (Mutti \& Normark, 1991) de um sistema de água profunda. Os elementos arquiteturais são definidos como corpos geológicos tridimensionais, caracterizados por forma, dimensão e distribuição das litofácies homogêneas. Não existe ainda uma precisa codificação dos elementos arquiteturais em sistema de água profunda (Pickering et al., 1995; Posamentier \& Walker, 2006), como ocorre em sistemas fluviais. Neste trabalho definiram-se cinco elementos arquiteturais na UA, que serão descritos a partir de suas distribuições volumétricas: Pelitos laminados e depósitos de escorregamento (slumping), Pelitos e sutis camadas de arenitos, Arenitos amalgamados, Arenitos com sutis camadas de pelitos, Conglomerados, arenitos e interestratificações de arenitos e pelitos.

PELITOS LAMINADOS E DEPÓSITOS DE ESCORREGAMENTO (SLUMPING) - SOPE LAMOSO Este elemento arquitetural está disseminado por toda a sucessão da UA, compondo aproximadamente $64,4 \%$ da unidade. Argilitos siltosos, azul-cinzento escuro, laminados, são os litotipos dominantes (Fig. 2A e B). As lâminas, ou camadas delgadas, são constituídas por arenitos muito fino, de $<1 \mathrm{~mm}$ até $2 \mathrm{~mm}$ de espessura, que gradacionam a argilitos siltosos, espessos até $2 \mathrm{~cm}$ (Fig. 2C). No lugar das lâminas de arenitos se observam, com relativa freqüência, pequenas marcas onduladas de corrente (current ripples) de arenitos muito finos, espessos de menos $1 \mathrm{~cm}$ a poucos milímetros (Fig. 2D). Pouco comuns são lâminas homogêneas, preto-azuladas, de argilitos siltosos espessos até $5 \mathrm{~mm}$. As lâminas ou 


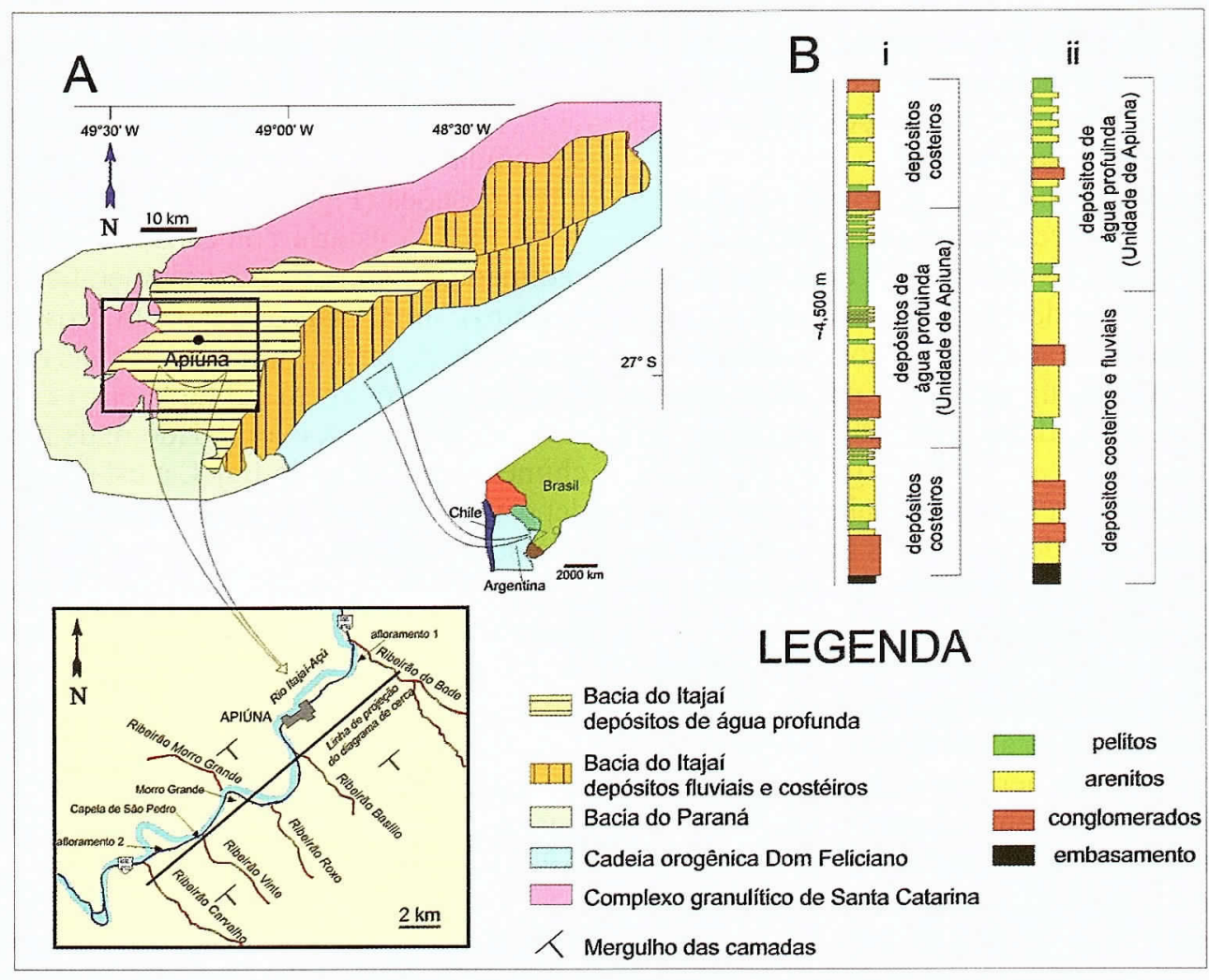

Figura 1 - Mapa geológico e modelos litoestratigráficos da Bacia do Itajaí. (A) Localização e mapa geológico esquemático da Bacia do Itajaí, simplificado de Rostirolla et al. (1999). (B) As duas principais interpretações estratigráficas da Bacia do Itajai: i) segundo Rostirolla et al. (1999) e ii) segundo Krebs et al. (1988).

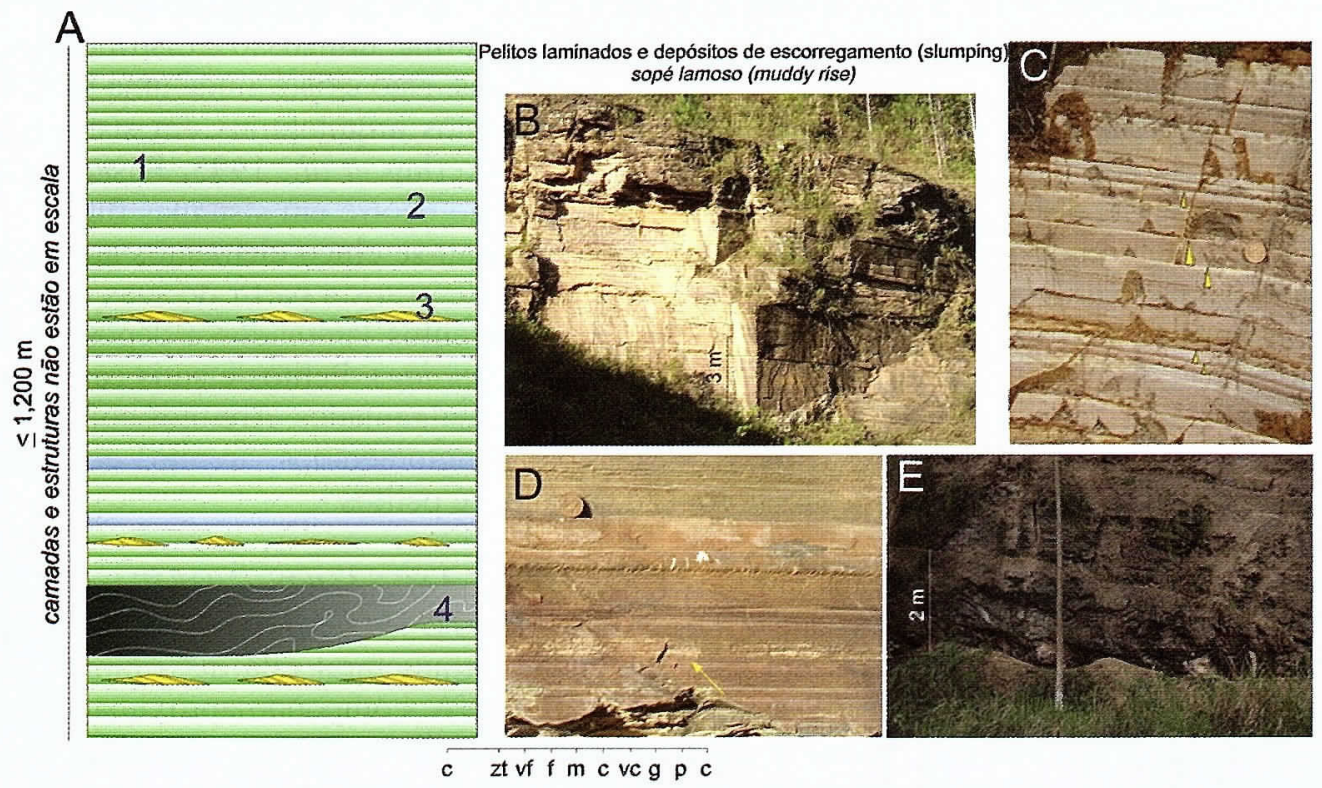

Figura 2 - Elemento arquitetural de Pelitos laminados e depósitos de escorregamento (slumping), interpretado como sopé lamoso. (A) Esquema estratigráfico do elemento. As camadas e as estruturas não são em escala. Litofácies: 1 - arenitos muito finos gradados a argilitos siltosos; 2 - argilitos siltosos homogêneos, cinza escuro; 3 - marcas de corrente isoladas; 4 - depósitos de escorregamentos. (B) Afloramento com pelitos laminados. Pedreira Schmidt, Riberão do Bode. (C) Arenitos muito finos gradados a argilitos siltosos. Os triângulos indicam as lâminas gradadas. (D) Marcas de corrente isoladas, indicadas pela seta. (E) Depósitos de escorregamento em pelitos laminados. As linhas indicam os limites das camadas. Mergulho a direita. Moeda: $2 \mathrm{~cm}$. 
sutis camadas, gradadas de arenito muito fino a pelito, são produtos de fluxos de muito baixa densidade e turbulentos. As lâminas de argilito siltoso, cinza escuras, podem ser identificadas como depósitos hemipelágicos. Depósitos de escorregamento (slumping) ocorrem nos pelitos laminados e formam corpos com base côncava e superfície superior plana, cuja espessura é entre poucos decímetros até $5 \mathrm{~m}$ e largura até $40 \mathrm{~m}$ (Fig. 2E). Acima de $3.500 \mathrm{~m}$ na sucessão estudada (Fig. 3) este elemento é o único observado.

Este elemento registra momentos de ausência de aporte de granulometria grossa na bacia, mas ainda sob domínio dos fluxos gravitacionais. As paleocorrentes registradas nestes depósitos (Fig. 4A e B) mostram valores análogos aos registrados nos outros elementos arquiteturais, que indicam um mergulho regional entre SW-SE.

Sucessões similares a estes pelitos laminados foram descritas por Walker (1975) como "zebra-striped" e interpretadas como depósitos de bacia. Entretanto as deformações pós-deposicionais (slumping) indicam condições de instabilidade da superfície deposicional, ligadas a alguma inclinação morfológica. Além disso, a freqüente associação horizontal e vertical deste elemento com depósitos de canal ou lençol proximal de areia sugere que não se tratam de depósitos de bacia abissal. A hipótese de que estes depósitos sejam de ta- lude também é excluída. De fato, o talude é uma área de bypassing dos fluxos gravitacionais e é caracterizado, sobretudo por depósitos hemipelágicos, que são pouco representados no elemento descrito. Este elemento arquitetural é interpretado como uma área de sopé constituída prevalentemente de lama (muddy rise) (Fig. 5).

PELITOS E CAMADAS DELGADAS DE ARENI$N A L \quad$ Este elemento é formado por interestratificações de pelitos e arenitos muito finos (Figs. 6A e B). Cada dupla arenito/pelito constitui um evento deposicional (Fig. 6C), que começa com uma camada de arenito muito fino ou fino, espessa entre 1 e $15 \mathrm{~cm}$, organizada de um até quatro sets de laminações cruzadas cavalgantes (climbing ripples) (Fig. 6D), que as vezes cobrem laminações plano-paralelas. Acima das laminações cruzadas seguem pelitos gradados de silte argiloso-arenoso até argilito siltoso. Deformações pós-deposicionais (laminações convolutas em arenitos e pequenos depósitos de escorregamentos - microslumping) também são observadas. As direções das paleocorrentes indicam um sentido de movimento SW-SE (Fig. 4C), em acordo os dados regionais. As camadas possuem uma continuidade lateral ao redor de $100 \mathrm{~m}$, terminações laterais em cunha (pinch-out) são relativamente freqüentes em afloramento.

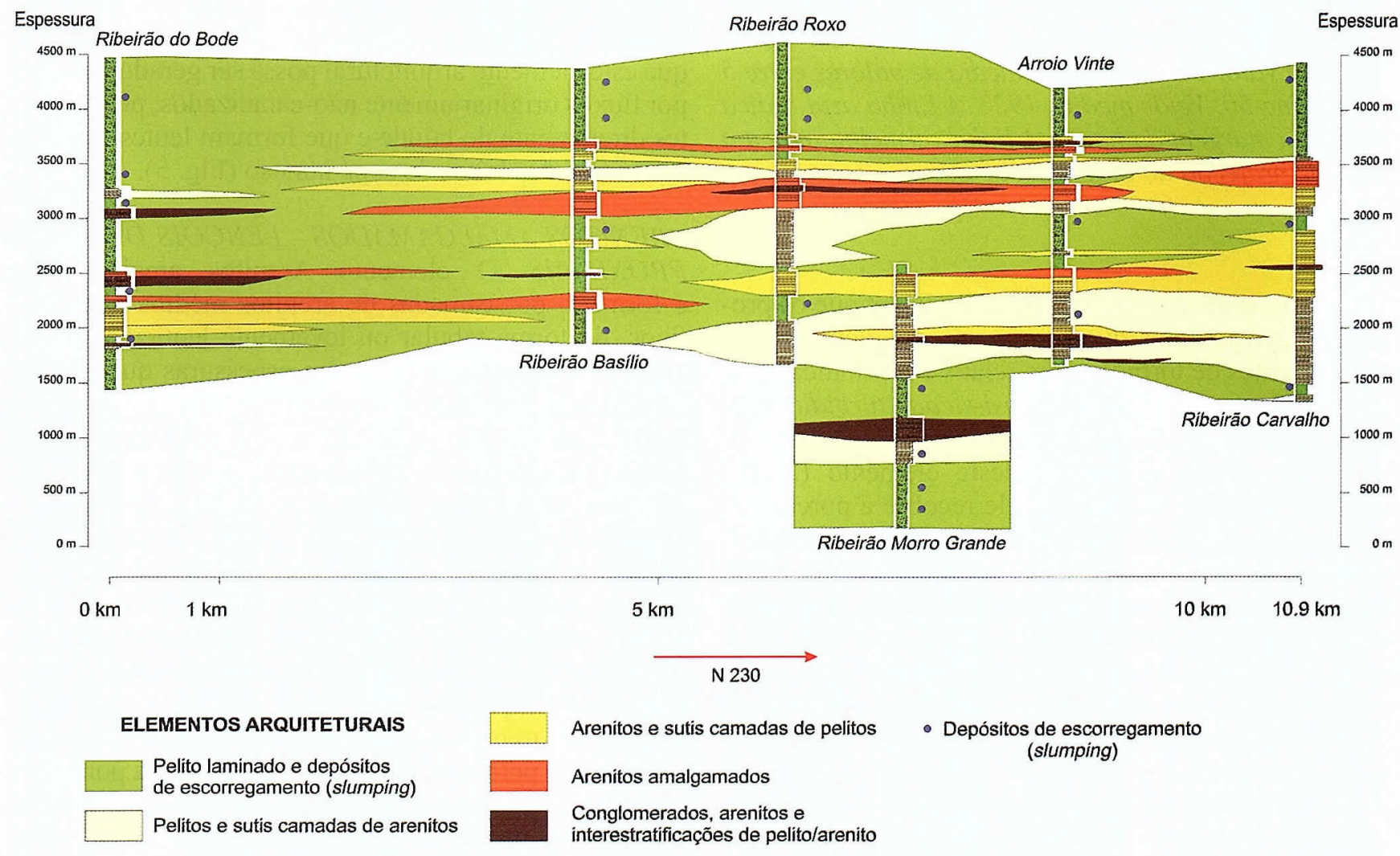

Figura 3 - Diagrama de cerca dos elementos arquiteturais da Unidade de Apiúna (UA). Este diagrama foi construído a partir de seções estratigráficas e um mapeamento geológico de detalhe. O diagrama interessa uma porção da UA espessa $4.500 \mathrm{~m}$, larga $10,9 \mathrm{~km}$ e longa $3 \mathrm{~km}$, que corresponde a cerca do $50 \%$ da extensão desta unidade em superficie. 

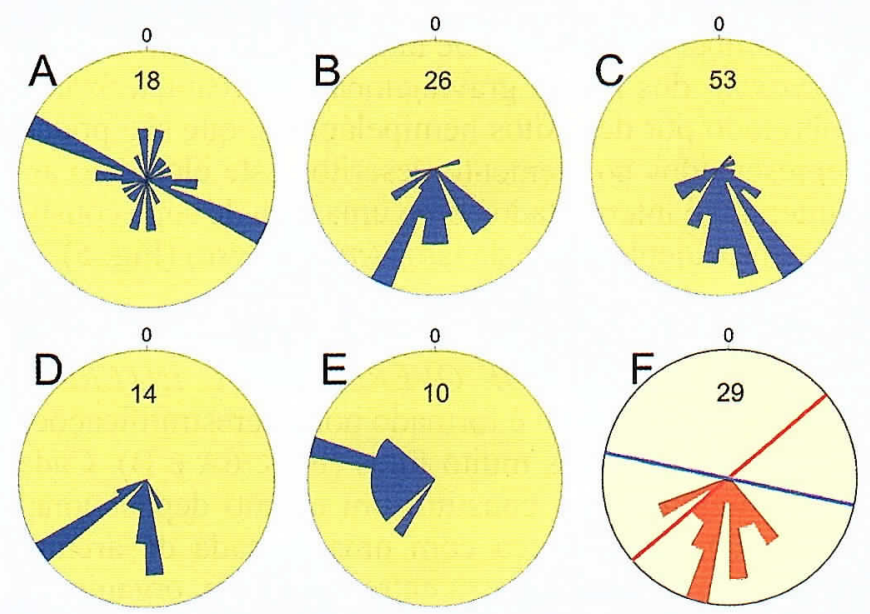

Figura 4 - Dados de paleocorrentes dos elementos arquiteturais. (A) Eixos das dobras dos depósitos de escorregamento no elemento Pelitos laminados e depósitos de escorregamento (slumping). (B) Direção dos foresets de marca de corrente do elemento Pelitos laminados e depósitos de escorregamento (slumping). (C) Dados do elemento Pelitos e sutis camadas de arenitos (marcas de corrente e marcas de sola). (D) Paleocorrentes da porção inferior do elemento Conglomerados, arenitos e interestratificações de arenitos e pelitos, interpretado como preenchimento de canal (marcas de sola). (E) Paleocorrentes da porção superior do elemento Conglomerados, arenitos e interestratificações de arenitos e pelitos, interpretado como sistema de diques marginais (marcas de corrente e de sola). (F) Histograma das paleocorrentes mostradas em figura 11. Cada valor corresponde à média de valores entre 5 e mais que 50. Vetor médio: $192^{\circ}$. A Linha azul indica a suposta margem da bacia. A linha vermelha indica a linha de projeção do diagrama de cerca.

As estruturas sedimentares indicam que os processos deposicionais que formaram este elemento foram correntes de turbidez com relativa continuidade no tempo (provavelmente tipo quasi-steady turbidity currents; Mulder and Alexander, 2001).

A melhor exposição deste elemento (Morro Grande, Fig. 1A), mostra que ele recobre a porção superior do elemento Conglomerados, arenitos e interestratificações de arenitos e pelitos, interpretada como diques marginais (veja parágrafo abaixo). Distinguese dos depósitos de diques marginais pelos seguintes pontos: i) maior difusão de pelitos; ii) indicadores de paleocorrentes em acordo com os dados de inclinação regional; iii) ausência de camadas de arenitos médio, mais espessas de $1 \mathrm{~m}$.

A gradual transição deste elemento a depósitos de diques marginais e a similaridade das litofácies e mecanismos deposicionais sugere que possa ser produzido pelos mesmos fluxos que se espalham aos lados dos canais (overspilling) e que geram diques marginais. Deste modo é possível interpreta-lo como depósito de overbank ou intercanal. Exclui-se a possibilidade de

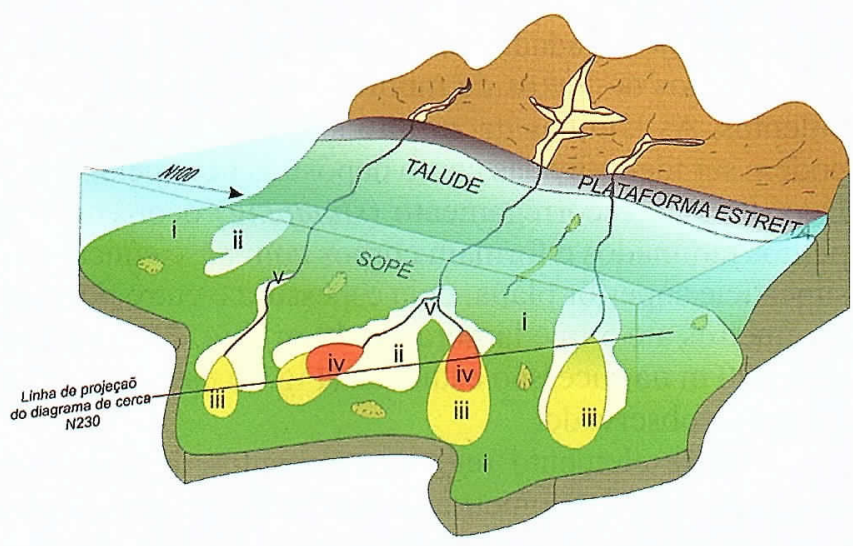

Figura 5 - Esquema da distribuição dos elementos arquiteturais e hipotética reconstrução do sistema deposicional. i) Pelitos laminados e depósitos de escorregamento - sopé lamoso; ii) Pelitos e sutis camadas de arenitos - depósitos de overbank ou de intercanal; iii) Arenitos amalgamados - lençóis de areia proximais; iv) Arenitos com sutis camadas de pelitos - lençóis de areia distais; v) Conglomerados, arenitos e interestratificações de arenitos e pelitos - sistema de canal e diques marginais.

que este elemento possa representar depósitos marginais de lençóis de areia distais, pois o mesmo não possui relações estratigráficas com o elemento Arenitos com sutis camadas de pelitos, interpretados como lençóis de areia distais. Todavia, não é possível excluir que este elemento arquitetural possa ser gerado também por fluxos originariamente não-canalizados, provenientes diretamente do talude e que formam lentes isoladas acima dos depósitos de sopé lamoso (Fig. 5).

ARENITOS AMALGAMADOS - LENÇÓIS DE AREIA PROXIMAIS O elemento Arenitos amalgamados é formado por camadas de arenitos médios o médiofinos, de forma tabular ou levemente lenticular (Figs. $7 \mathrm{~A}$ e B). As camadas possuem espessuras que variam de 0,15 até $4 \mathrm{~m}$, em média $1.5 \mathrm{~m}$, são mais de $60 \mathrm{~m}$ largos (em direção perpendicular às paleocorrentes). Estas camadas se sobrepõem em ciclos de compensação formando corpos espessos entre 20 e 200 m (Fig. 3), com conteúdo de areia maior de $90 \%$. Cada camada arenosa é bipartida em uma porção inferior, até 95\% da espessura da camada, e outra superior (Fig. 7C). A porção inferior é constituída por arenitos médios ou médio-grosseiros, sem estruturas sedimentares ou com carpetes de tração e intraclastos flutuantes. A porção superior é de arenitos muito finos, que passam a arenitos pelíticos ou pelitos areníticos, é caracterizada por laminações plano-paralelas e laminações cruzadas. A falta de depósitos pelíticos causa amalgamação das camadas areníticas. Às vezes corpos mais finos, lenticulares, espessos até $2 \mathrm{~m}$, largos até $30 \mathrm{~m}$ e caracterizados por alternâncias de sutis camadas de arenitos muito finos e pelitos arenosos separam os corpos deste elemento arquitetural (Fig. 7D). 


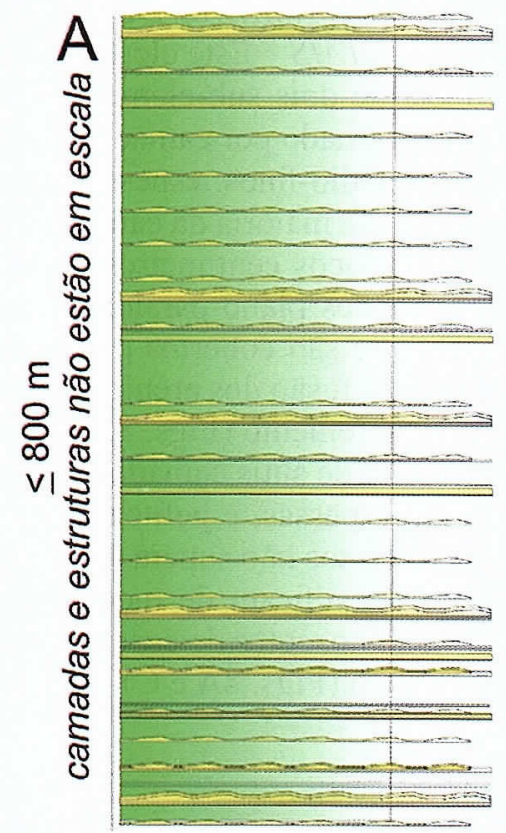

Pelitos e sutis camadas de arenitos depósitos de overbank ou de intercanal
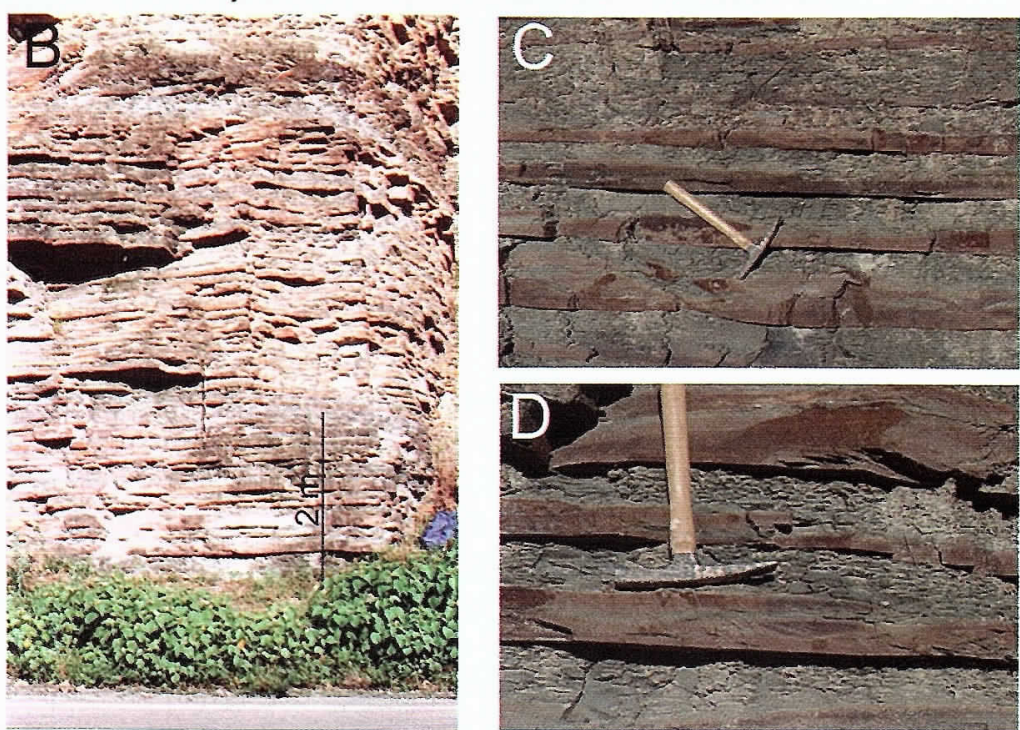

c zt vf $f \mathrm{~m} \subset \mathrm{vc} g \mathrm{p} \mathrm{c}$

Figura 6 - Elemento arquitetural de Pelitos e sutis camadas de arenitos, interpretados como depósitos de overbank ou de intercanal. (A) Esquema estratigráfico do elemento. As camadas e as estruturas não são em escala. (B) Afloramento de Morro Grande. A relação arenito:pelito é 1:5. (C) Camadas de pelitos e arenitos interestratificados. Os pelitos são gradados. (D) Três set de marcas cavalgantes produzidas por corrente de turbidez.

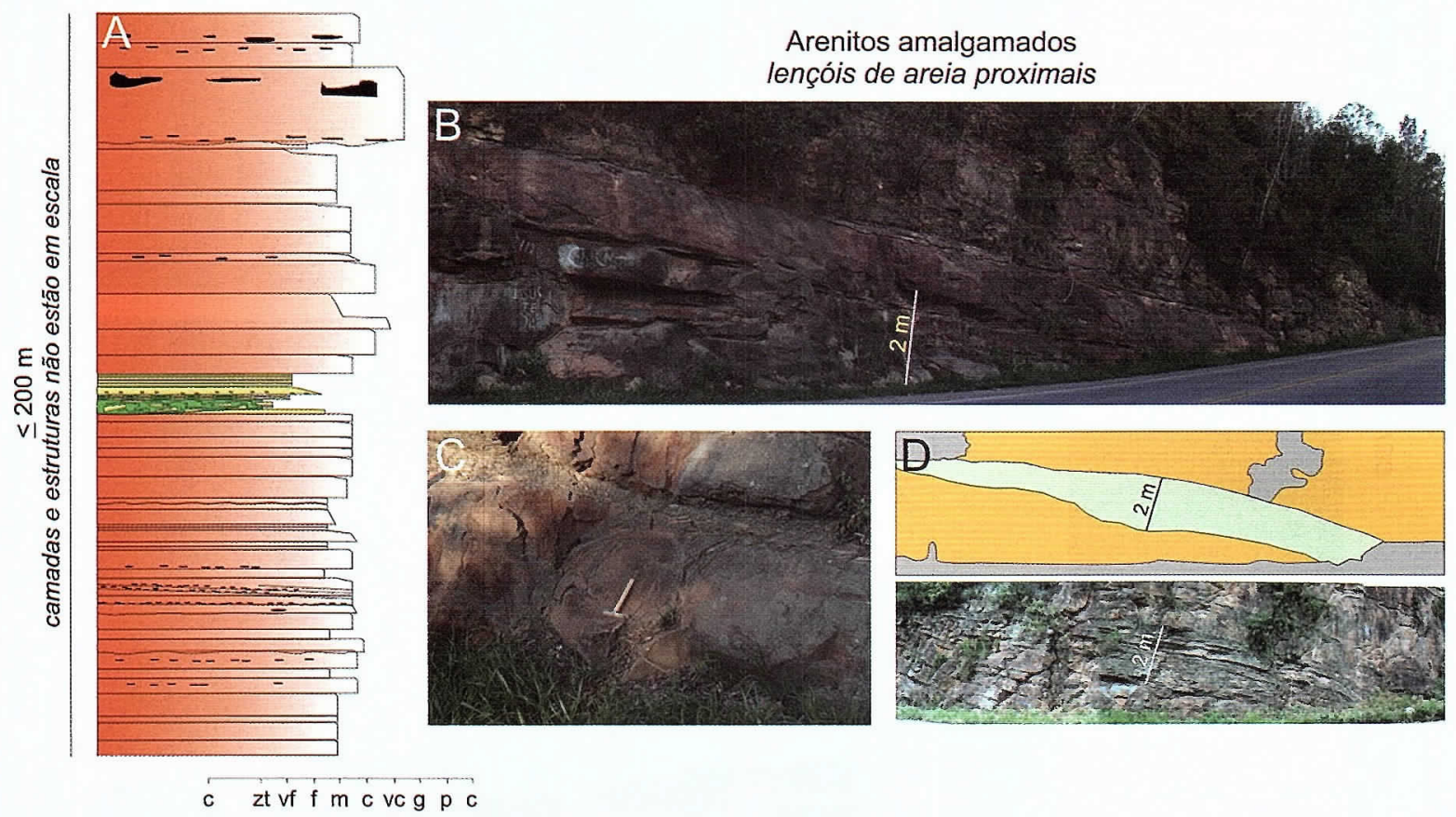

Figura 7 - Elemento arquitetural de Arenitos amalgamados interpretados como lençóis de areia proximais. (A) Esquema estratigráfico do elemento. As camadas e as estruturas não são em escala. (B) Camadas de arenitos de forma tabular o levemente lenticular. (C) Arenitos bipartidos, com porção inferior de arenitos medio-fino, sem estruturas, e uma porção superior com arenitos muito finos, com estruturas de tração. (D) Camadas lenticulares até $2 \mathrm{~m}$ espessas de arenitos alternados com pelitos; estas camadas são interpretadas como interrupção autocíclica da construção dos lençóis de areia. Martelo: $28 \mathrm{~cm}$. 
A dualidade das características litológicas sugere que estas camadas são produzidas por fluxos de gravidade bipartidos (Sanders, 1965). A porção inferior da camada gerada por um fluxo mais denso e a parte superior por um fluxo com menor concentração de sedimentos e turbulento. Estes tipos de fluxos são chamados por Mulder \& Alexander (2001) de fluxos de densidade concentrados e podem corresponder a correntes de turbidez de alta concentração de Lowe (1982). A base não erosional e a alta relação de largura:espessura mostram que estes corpos são formados por fluxos não canalizados e podem ser assim atribuídos a lençol de areia (também chamados de lobos ou splays frontais; Posamentier \& Walker, 2006). As intercalações lenticulares, mais finas, testemunham fases de interrupção do fornecimento de areia, provavelmente ligados à migração lateral da construção do lençol de areia.
ARENITOS COM SUTIS CAMADAS DE PELITOS LENÇÓIS DE AREIA DISTAIS Este elemento é constituído pela alternância de dois sub-elementos. O primeiro (Figs. 8A e B) é formado por camadas bipartidas de arenitos médios ou médio-finos, espessas entre 25 $180 \mathrm{~cm}$, sem estruturas pela maioria da camada; na porção superior passam a poucos centímetros de arenitos muito fino, com laminações plano-paralelas e marcas onduladas de corrente que são cobertos por pelitos de até $5 \mathrm{~cm}$ de espessura. A difusão dos arenitos é ao redor de $90 \%$. O segundo sub-elemento (Figs. $8 \mathrm{~A} \mathrm{e} \mathrm{C)} \mathrm{é} \mathrm{for-}$ mado por uma alternância de sutis camadas de arenitos muito finos, $1,5-25 \mathrm{~cm}$ espessas, e pelitos, $4-9 \mathrm{~cm}$ espessos. A difusão dos arenitos não supera $40 \%$. Os dois sub-elementos se interestratificam de modo aparentemente irregular, formando pacotes de espessura entre 2 e $9 \mathrm{~m}$, largos mais de $70 \mathrm{~m}$ (Figs. 8A e C).

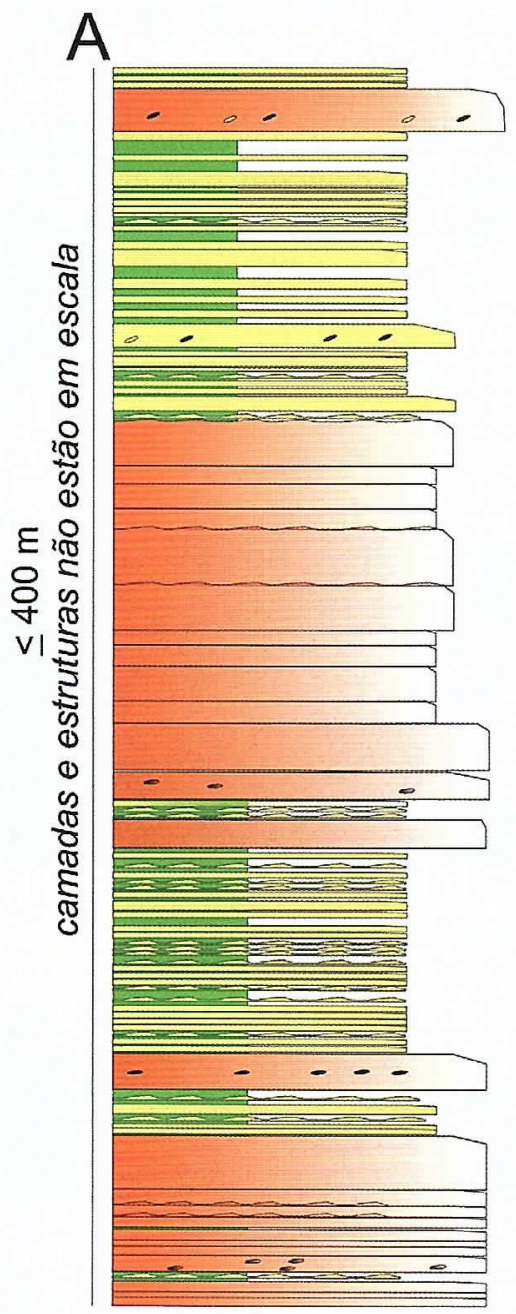

\section{Arenítos e sutis camadas de pelitos lençóis de areia distais}

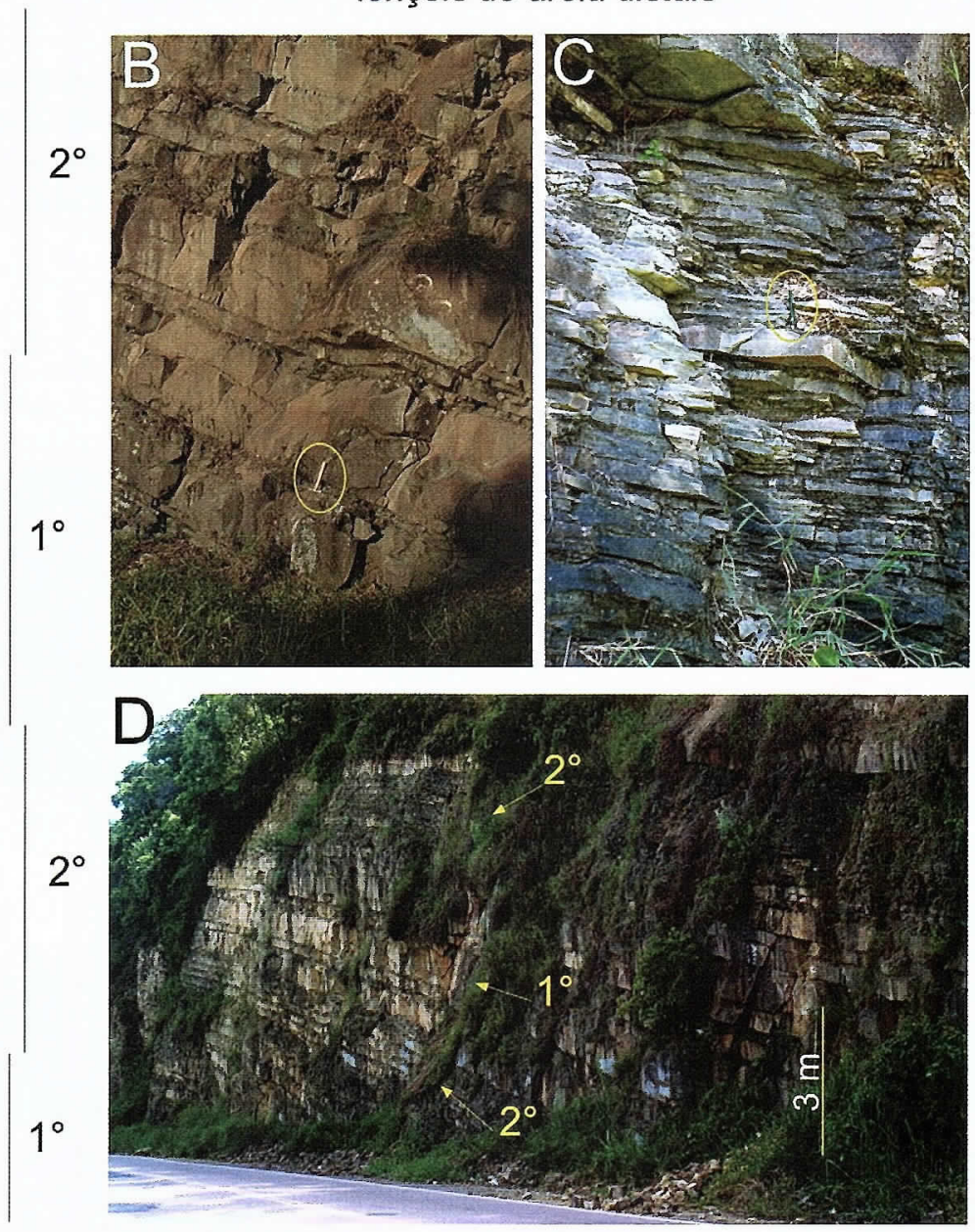

c zt vf $f$ m c vc g p c

Figura 8 - Elemento arquitetural de Arenitos com sutis camadas de pelitos interpretados como lençóis de areia distais. (A) Esquema estratigráfico que mostra os dois sub-elementos arquiteturais: $1^{\circ}$ primeiro sub-elemento; $2^{\circ}$ - segundo sub-elemento. (B) O primeiro sub-elemento é formado por arenitos bipartidos e amalgamados. (C) O segundo sub-elemento é formado por interestratificações de sutis camadas de arenitos e pelitos. (D) Alternâncias irregulares dos dois sub-elementos. Martelo: $28 \mathrm{~cm}$. Lapiseira: $15 \mathrm{~cm}$. 
Este elemento arquitetural mostra freqüentes transições verticais com Arenitos amalgamados e com Pelitos laminados e depósitos de escorregamento (slumping) (Fig. 3). Basilici (2006) interpretou este elemento como expressão distal do elemento Arenitos amalgamados usando, como chave para interpretação, um modelo de trato de fácies em que um fluxo concentrado bipartido transforma-se em um fluxo completamente diluído de corrente de turbidez, gerando na parte proximal corpos arenosos amalgamados, espessos até 4 m, (Arenitos amalgamados) e, na parte distal, alternâncias de arenitos e pelitos (Arenitos com sutis camadas de pelitos). Neste contexto este elemento arquitetural é interpretado produto deposicional da porção distal de lençóis de areia.

CONGLOMERADOS, ARENITOS E INTERESTRATIFICAÇÕES DE ARENITOS E PELITOS - DEPÓSITOS DE CANAL E DIQUE MARGINAL Este elemento é formado por uma parte inferior (conglomerados e arenitos), que constitui o preenchimento de um canal, e uma parte superior (interestratificações de arenitos e pelitos), que forma os depósitos de dique marginal (Fig. 9A).
A melhor exposição deste elemento (Afloramento n.2; Fig. 1A) mostra que a parte inferior possui uma espessura de $21 \mathrm{~m}$, e uma relação largura:espessura $<16$. Acima de uma superfície erosional, côncava, observa-se uma seqüência de depósitos gerados por fluxos gravitacionais com granulometrias e espessuras progressivamente menores. Um depósito com característica intermediária entre depósito de fluxo de detrito e depósitos de escorregamento plástico (Fig. 9B), que Stow \& Johnson (2000) chamaram de flow-slide, cobre a base erosional. Cinco episódios lenticulares de arenitos conglomeráticos (Fig. 9C), espessos entre 50 e $300 \mathrm{~cm}$, sem estruturas sedimentares ou com uma mal definida gradação, contendo superfícies superiores e inferiores erosivas, seguem na sucessão vertical. Eles são interpretados como depósitos de fluxos hiperconcentrados (Mulder \& Alexander, 2001) ou fluxos granulares (Lowe, 1982). Arenitos médios, de forma tabular ou lenticular, às vezes com base erosional, espessos entre 40 e $150 \mathrm{~cm}$, terminam a parte inferior deste elemento arquitetural (Fig. 9D). Eles são interestratificados com pacotes, até $40 \mathrm{~cm}$ espessos, de camadas delgadas de arenitos e pelitos. Estes corpos são interpretados como produtos de fluxos concentrados (Mulder \& Alexander,

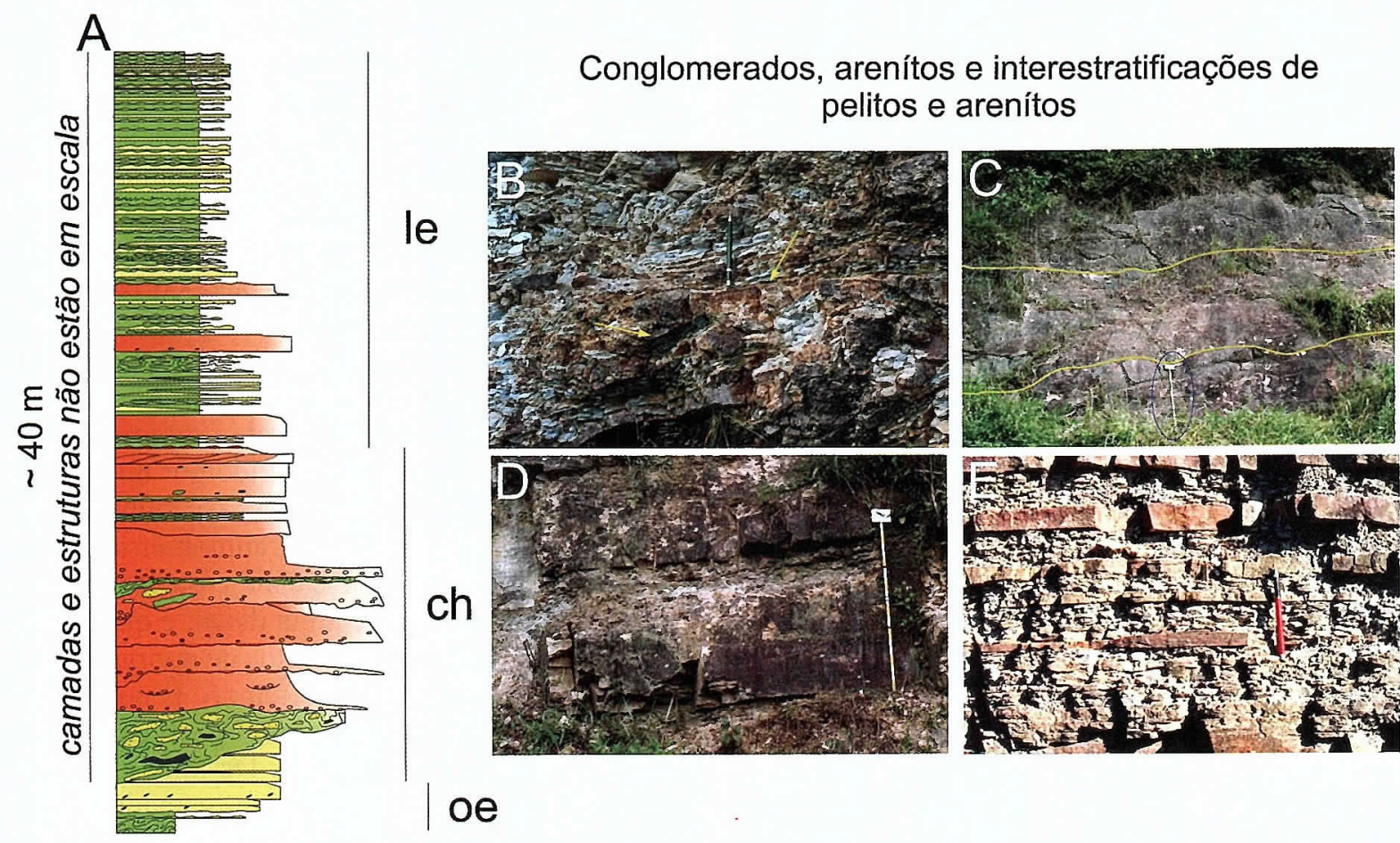

c zt vf $\mathrm{f}$ m c vc g p c

Figura 9 - Elemento arquitetural de Conglomerados, arenitos e interestratificações de arenitos e pelitos, interpretado como sistema de canal e diques marginais. (A) Esquema estratigráfico deste elemento. ch: canal. le: diques marginais. oe: outros elementos. (B) Depósitos de flow-slide na base do canal. As setas indicam intraclastos de arenitos e pelitos. (C) Arenitos conglomeráticos na porção inferior. As linhas indicam a base erosiva das camadas. (D) Arenitos bipartidos no topo do preenchimento do canal. (E) Depósitos de diques marginais na parte alta deste elemento. Lapiseira: $14 \mathrm{~cm}$. Bastão de Jacob: $1,5 \mathrm{~m}$. 
2001). As paleocorrentes registradas na parte inferior deste elemento correspondem aos valores regionais extraídos dos outros elementos, indicando direções S-SW (Figs. 4D e F). Esta porção inferior é interpretada como preenchimento de um canal devido à sua base côncava e erosiva, e ao tipo de preenchimento que é caracterizado por fluxos gravitacionais de alta densidade que se desenvolvem mais facilmente em estruturas confinadas.

A parte superior deste elemento arquitetural no Afloramento 2 (Fig. 1A) é espessa $15 \mathrm{~m}$. Ela é constituída por arenitos lenticulares, $2-40 \mathrm{~cm}$ espessos, caracterizados por marcas onduladas de corrente, alternados com pelitos arenosos, espessos $<3-25 \mathrm{~cm}$ (Fig. 9E). A dupla arenitos/pelitos constitui um único evento deposicional como é testemunhado pela gradação. As camadas de arenito mostram forma lenticular com freqüentes terminações laterais em cunha, laminações convolutas, laminações cruzadas cavalgantes. As marcas onduladas de correntes indicam fluxos a alto angulo (na direção de W, Fig. 4E) em relação aos valores registrados na parte inferior do elemento. Camadas de arenito médio, às vezes com base erosional, espessas de 60 até 115 $\mathrm{cm}$, são presentes na base desta sucessão. Esta porção é atribuída a depósitos de dique marginal pelos seguintes motivos: i) a transição de depósitos de canal é gradual; ii) as paleocorrentes indicam fluxos a alto angulo em relação à direção de fluxo do canal principal, sugerindo fluxos que se distribuíam lateralmente ao sair do canal. iii) A forma lenticular das camadas é considerada por vários autores (Mutti, 1977; Kirschner \& Bouma, 2000; Posamentier \& Walker, 2006) típica de depósitos de dique marginal. iv) Outras estruturas sedimentares como laminações cruzadas cavalgantes (climbing ripples), laminações convolutas são estruturas descritas em diques marginais.

Arquitetura do Sistema Deposicional de Água Profunda Rico em Lama Mediante a medição de oito seções e um mapeamento geológico foi obtido um diagrama de cerca que abrange uma área espessa $4.500 \mathrm{~m}$, larga (a alto angulo em relação às paleocorrentes) 10,9 $\mathrm{km}$ e profunda $3 \mathrm{~km}$ (Fig. 3 ).

Pelitos laminados e depósitos de escorregamento é o elemento arquitetural dominante: ele constitui $64.4 \%$ da sucessão estudada. É difundido da base até o topo da unidade e envolve todos os outros elementos arquiteturais. Este elemento parece constituir a superfície, acima da qual se depositaram todos os outros elementos. Pelitos e sutis camadas de arenitos constituem $20.6 \%$ da sucessão, se distribuem uniformemente da base até $3.300 \mathrm{~m}$. Este elemento forma corpos com extensão lateral até $8 \mathrm{~km}$ e com espessura até $800 \mathrm{~m}$. Arenitos amalgamados são difundidos entre 2.000 e 3.500 $\mathrm{m}$ no diagrama de cerca, constituem $6.6 \%$ e formam corpos largo até $7 \mathrm{~km}$ e espessos até $200 \mathrm{~m}$. Arenitos com sutis camadas de pelitos constituem $5.7 \%$, estão difundidos entre 1.500 e $3.500 \mathrm{~m}$ no diagrama de cerca e formam corpos até $8 \mathrm{~km}$ largos e $400 \mathrm{~m}$ espessos. O elemento denominado Conglomerados, arenitos e interestratificações de arenitos e pelitos forma 10 comple- xos de depósitos de canais e diques marginais; ele constitui $2.7 \%$ da UA. Este elemento é mais freqüente na porção inferior da sucessão (abaixo $2.000 \mathrm{~m}$ de cota), formando corpos espessos até $200 \mathrm{~m}$ e largos até $3 \mathrm{~km}$. As dimensões, em particular a espessura, diminuem na parte superior da sucessão.

A principal característica do sistema de água profunda da AU é a abundância de argilitos. A maior parte dos argilitos é produzida por fluxos gravitacionais de baixa densidade; só um mínimo percentual é atribuído a depósitos hemipelágicos. Stanley \& Maldonado (1981) descrevem uma situação análoga na bacia Helênica, onde a maioria dos pelitos é formada por correntes de turbidez de baixa densidade. Tal característica permite definir a UA como um sistema de água profunda dominado de deposição gravitacional de granulometria fina.

Conglomerados, arenitos e interestratificações de arenitos e pelitos, Arenitos amalgamados e Arenitos com sutis camadas de pelitos constituem corpos comumente associados entre eles, tanto em sucessão vertical como horizontal. A associação destes elementos constrói corpos de maiores dimensões (até $8 \mathrm{~km}$ largos e até $500 \mathrm{~m}$ espessos), localmente separados por sutis pacotes de poucos metros de argilitos laminados.

A análise da distribuição das paleocorrentes ao longo do diagrama de cerca mostra uma limitada variação lateral e vertical dos vetores. Estes oscilam entre $245^{\circ}$ e $140^{\circ}$, mas estão sobretudo concentrados entre $200^{\circ}$ e $170^{\circ}$ (Fig. 10). Estes valores indicam que os vetores de direção dos fluxos gravitacionais, ao longo de uma faixa larga $10.9 \mathrm{~km}$, eram paralelos entre eles e assim permaneceram por toda a evolução da UA.

A forma lenticular dos elementos de granulometria grossa e as direções das paleocorrentes sugerem que o sistema de alimentação dos corpos deposicionais era múltiplo e que assim se manteve durante toda a sedimentação da AU. Cada complexo de canal e dique marginais e/ou de lençol de areia proximal e/ou lençol de areia distal foi assim produzido por um único ponto de aporte. No diagrama de cerca se reconhecem 15 diferentes corpos lenticulares de granulometria grossa (Fig. 3) que são formados por canais e/ou lençóis de areia proximal e/ou lençóis de areia distal, e que podem corresponder a 15 diferentes pontos de aporte de sedimento, isolados, no espaço e no tempo. É pouco provável que os múltiplos distribuidores fossem gerados por um único grande sistema deltaico. De fato: (1) as características petrográficas de diferentes camadas de arenitos e conglomerados mostram uma grande variabilidade, e por isto indicam que os pontos de aporte que alimentavam os sistemas profundos eram caracterizados por diferentes bacias de drenagem; (2) um sistema deltaico com vários distribuidores implica a presença de um sistema fluvial de dimensões suficientes para gerar areias com alto grau de maturidade mineralógica e textural, ao contrário, os arenitos da UA mostram baixa maturidade (arenitos arcóseos com clastos angulosos ou subangulosos) (Rigon, 1993). Por isto é mais provável que os sistemas de alimentação da bacia profunda da UA eram 


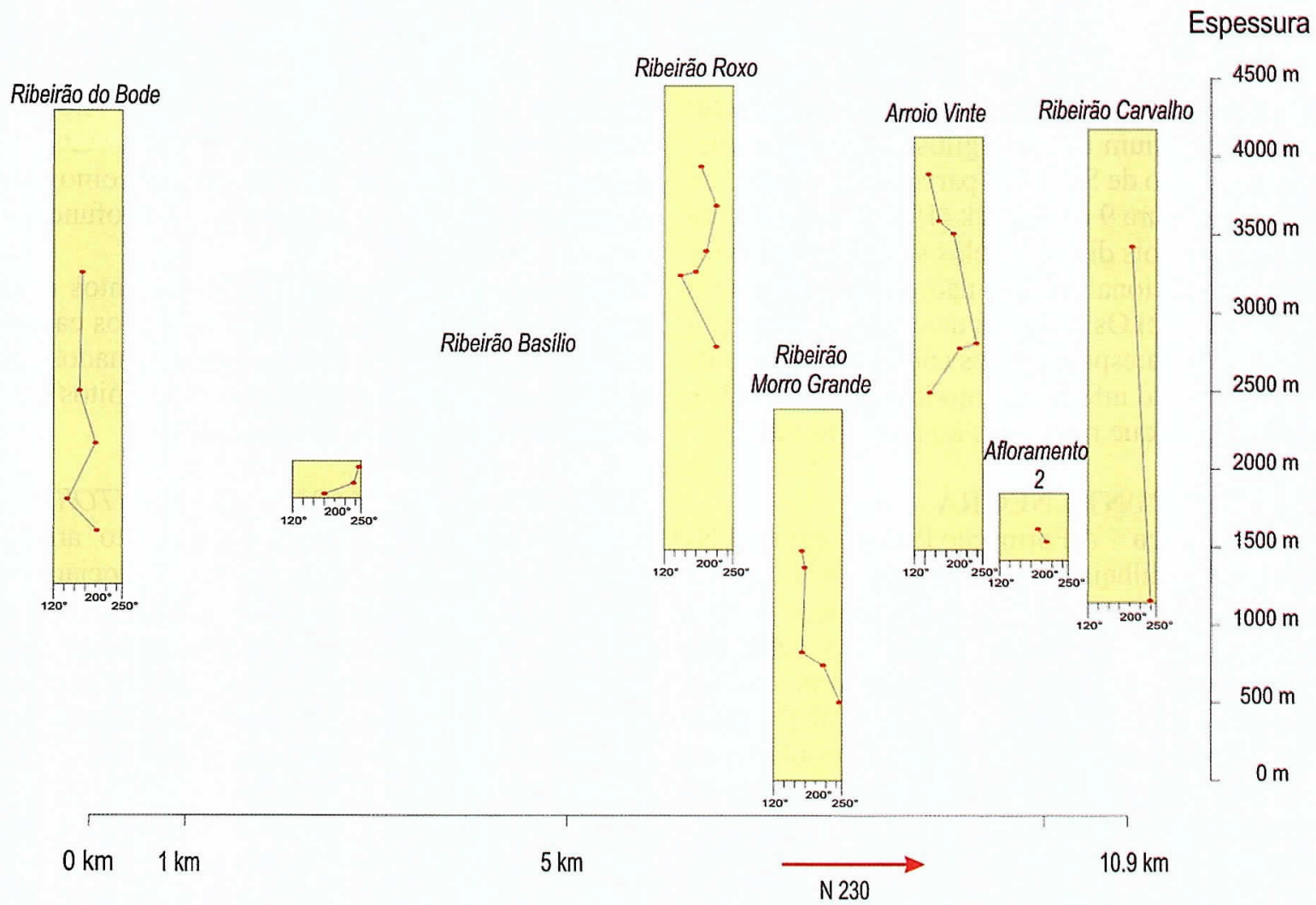

Figura 10 - Valores médios dos indicadores de paleocorrentes nas seções estudadas. Os valores são extraidos de todos os elementos arquiteturais e são valores médios de medida pontuais que variam de 4 a 52. As distâncias proporcionais das seções são mantidas.

constituídos por pequenos sistemas fluviais, caracterizados por restritas bacias de drenagem, que após um breve percurso, jogavam material clástico grosso nas áreas mais profundas através de uma plataforma estreita (Fig. 5).

Bouma (2000 e 2004) descreve dois modelos de sistemas de água profunda: um modelo de granulometria grossa e um modelo de granulometria fina. Muitas das características descritas pelos modelos da UA se adaptam ao modelo de Bouma de granulometria fina: i) A relação arenito:argillito é baixa. ii) $\mathrm{O}$ volume do sedimento é muito alto. iii) A tendência de deformações pós-deposicional, como escorregamentos plásticos (slumping) é alta. iv) $\mathrm{O}$ desenvolvimento de diques marginais é bom. v) Os depósitos de overbank ou intercanal são constituídos por material fino. vi) $\mathrm{O}$ transporte no interno da bacia é eficiente, como testemunhado pela posição dos canais ou dos sistemas de lençóis de areia que se estendem acima do sopé lamoso (muddy rise). vii) As estruturas dos corpos areniticos que constituem os lençóis de areia da UA são análogas a aquelas descritas no modelo de Bouma. Todavia, existem alguns aspetos que diferenciam em modo substancial o modelo de Bouma do sistema da UA: i) No modelo de Bouma o transporte continental do material clástico é muito longo e provoca uma alta maturidade textural e mineralógica dos arenitos e dos conglomerados; no modelo da UA arenitos e conglomerados mostram uma baixa maturidade, testemunhando um breve período de transporte continental do material clástico. ii) A distribuição granulométrica dos depósitos da UA é muito mais variada de que aquela mostrada no modelo de Bouma. iii) Os canais da UA são de menores dimensões 16:1 (largura:espessura), enquanto no modelo de Bouma possuem valores 40-80:1 (largura:espessura). iv) O sistema de alimentação da UA não era um único delta, mas uma série de pequenos rios. v) A tripartição do sistema que Bouma usa (inner-upper, middle-mid, outer-lower) não é aplicável ao modelo da UA, devido a distribuição irregular dos corpos grosseiros no sopé lamoso. vi) Uma ampla plataforma continental caracteriza o modelo de Bouma. Entretanto, a imaturidade e a grande variedade petrográfica dos depósitos da UA são provavelmente ligadas também à inexistência de uma plataforma continental ampla que teria permitido uma maior maturidade e uma homogeneização petrográfica dos arenitos.

Reading \& Richards (1994) e Richards (1996) constroem 12 modelos função do modo de aporte (pontual, múltiplo ou linear) e do tipo de aporte (ricos em: argila, argila-areia, areia, cascalho). Tendo em consideração o tipo e modo de aporte do sistema da UA pode-se associar ao modelo de rampa rico em pelito. As características deposicionais, descritas por Reading \& Richards (1994), que mais se adaptam a modelo da UA são: i) a prevalência de depósitos não canalizados, ii) as pequenas dimensões dos canais, iii) a maior extensão do sistema pela abundância de argila. 
Um modelo rico em pelito, semelhante ao sistema da UA, é o descrito por Surlick (1987). Neste modelo há a deposição de canais estreitos e prevalentes lençóis de arenito num talude argiloso. Embora o quadro geral do modelo de Surlick é parecido ao modelo da UA (compare à figura 9 de Surlick (1987) com a Figura 5 deste texto), os dois diferem pelos seguintes motivos. (1) A base deposicional da UA não é um talude, mas um sopé lamoso. (2) Os sistemas de canais diferem por uma relação largura:espessura dos canais do modelo de Surlick ( 1:1) muito inferior do modelo da UA (16:1) e pela ausência de dique marginais no primeiro modelo.

\section{A FORMAÇÃO PUNTA NEGRA}

Contexto Geológico A Formação Punta Negra (FPN) é parte da Pré-Cordilheira Argentina, que constitui uma unidade morfo-estrutural alongada em direção N-S, a leste da Cordilheira dos Andes Frontal e a oeste das Serras Pampianas, que abrange as provícias de San Juan, Mendoza e La Rioja (Fig. 11). A FPN foi gerada no Devoniano numa área de antepaís resultante da colisão entre a microplaca Chilênia e borda Oeste do Gondwana (Bustos \& Astini, 1997).

A FPN é uma unidade siliciclástica com mais de $1000 \mathrm{~m}$ de espessura que abrange uma área de exposição de aproximadamente $300 \mathrm{~km}$. Esta unidade representa a transição de depósitos de plataforma continental (representada pela Formação Talacasto) para uma área a deposição mais profunda caracterizada por depósitos gravitacionais (FPN).

A FPN é composta predominantemente pela intercalação por arenitos, variando de médios a areni- to siltosos, interpretados como sendo depositados pela ação de fluxos turbidíticos em ambiente subaquático profundo (Gonzales Bonorino \& Middleton, 1976). Astini (1990), Bustos (1996) e Bustos \& Astini (1997) interpretam os depósitos desta unidade como resultado da progradação de um delta em águas profundas.

Elementos Arquiteturais Três elementos arquiteturais foram reconhecidos na FPN: Arenitos canalizados (depósitos de canais), Arenitos amalgamados (depósitos de lençol de areia proximal) e Arenitos delgados (Depósitos de lençol de areia distal).

\section{ARENITOS CANALIZADOS - DEPÓSITOS PREEN-} CHIMENTO DE CANAIS O elemento arquitetural Arenitos canalizados é formado pela associação de camadas areníticas originadas por preenchimento de canal. Este elemento é composto por camadas com geometria lenticular (plano-côncava) agrupadas em sucessões sedimentares até $40 \mathrm{~m}$ espessas que podem atingir até $300 \mathrm{~m}$ de largura, formando litossomas de Arenitos amalgamados (Figs. 12 A e B).

Cada camada possui contato inferior erosivo, geometria de base côncava para cima e topo plano, podendo ser ligeiramente ondulado. Corpos canalizados são espessos no eixo e tornam-se mais delgados em direção às margens. A espessura das camadas varia de $0,5 \mathrm{a}$ 2,5 m (Fig. 12C). Os contatos basais são caracterizados por superfícies côncavas preenchidas por sedimentos mais grossos. Internamente estes corpos sedimentares são bipartidos, compostos por duas porções bem definidas: uma porção inferior maciça formada de arenitos

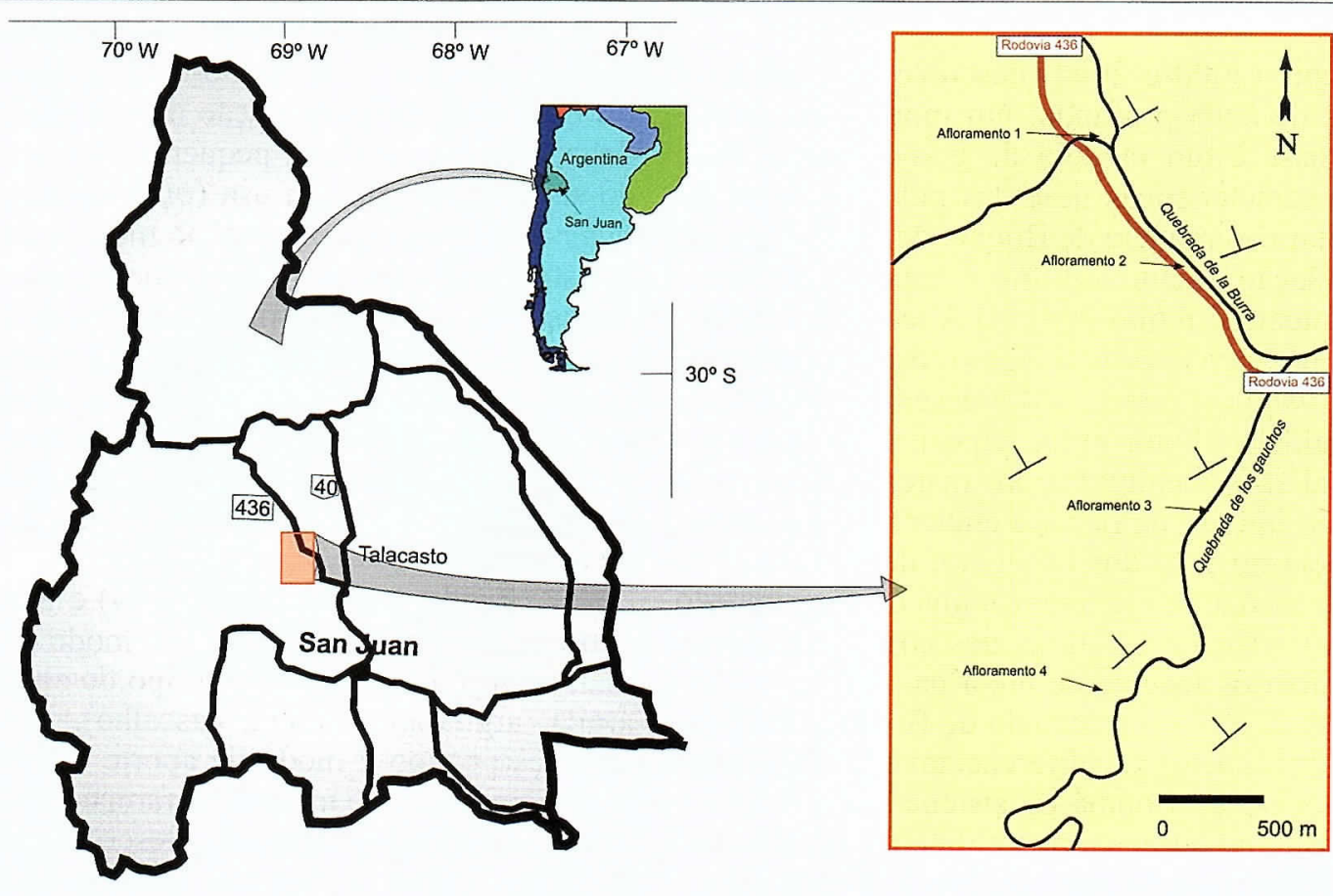

Figura 11 - Localização da Formação Punta Negra. 
Arenitos canalizados - depósitos de canal
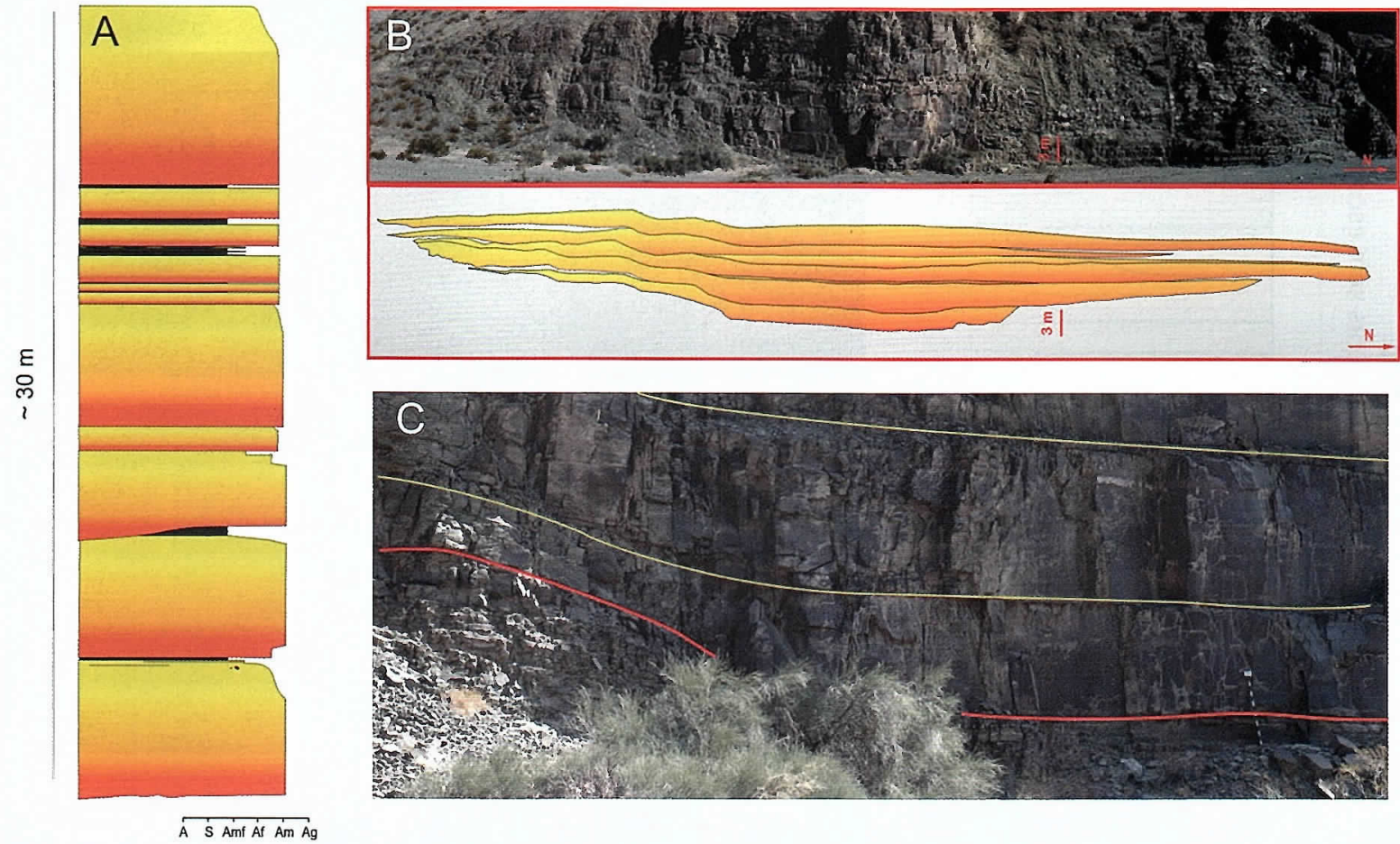

Figura 12 - Elemento arquitetural de Arenitos canalizados interpretados como depósitos de canais. (A) Esquema estratigráfico do elemento. As camadas e as estruturas não estão em escala. (B) Sucessão de camadas de preenchimento de canal com geometria côncavo-plana formadas por arenitos médios e médio finos. (C) Sucessão de camadas de preenchimento de canal amalgamadas. A linha vermelha indica o limite do canal composto e as linhas amarelas indicam superficies basais erosivas das camadas.

médio a médio-fino cinza-esverdeados, contendo grãos sub-angulares à sub-arredondados e moderada seleção, e uma porção superior formada por areia fina, bem selecionada contendo laminação plano-paralela e marcas onduladas de corrente. A porção superior é mais delgada compreendendo menos de $15 \%$ da espessura total da camada. A transição entre as duas porções é brusca, marcada pela súbita diminuição de granulação.

As camadas que compõem este elemento são formadas pela atuação de fluxos gravitacionais confinados. Os pacotes de arenito maciços são típicos de depósitos formados por fluxos de densidade concentrados (concentrated density flows) descritos por Mulder \& Alexander (2001) e/ou de fluxos arenosos densos (san$d y$ dense flows) sensu Tinterri et al. (2003). Segundo Tinterri et al. (2003), o principal mecanismo de suporte das partículas durante este tipo de fluxo é a interação grão-grão. Esta interação gera uma pressão dispersiva que ajuda a mantê-los em suspensão durante o transporte, ela também causa a desaceleração do fluxo por meio da dissipação de energia devido a colisões nãoelásticas.

A presença de dois setores com características distintas nas camadas bipartidas reflete a atuação de um fluxo gravitacional bipartido. Este tipo de fluxo é caracterizado por uma componente basal de maior densidade inferior e uma componente superior mais diluída e tur- bulenta (Tinterri et al., 2003).

Em geral os litossomas de preenchimento de canais possuem atributos internos e dimensões limitadas e seus registros não atingem grandes espessuras. As camadas deste elemento são interconectadas somente pelos eixos dos canais, sendo parcialmente segregadas.

Os depósitos deste elemento estão incisos em depósitos dos demais elementos arquiteturais, ocorrendo sobre os Depósitos de lençóis de areia distais e interdigitados com corpos de Depósitos de lençol de areia proximal. A associação de camadas acanaladas foi gerada durante eventos gravitacionais multifásicos confinados a canais (multistory channel).

Os corpos deste elemento são formados pelo preenchimento de canais pouco profundos e de extensões laterais relativamente limitada. As pequenas dimensões dos canais associada à ausência de depósitos de diques marginais e depósitos de overbank permitem classificar estes depósitos como depósitos de canais distributários.

ARENITOS AMALGAMADOS - DEPÓSITOS DE LENÇOL DE AREIA PROXIMAL Os depósitos de lençóis de areia proximal são caracterizados por extensos corpos de arenito de geometria plano-convexa. Este elemento consiste de sucessivas alternâncias entre camadas de arenitos maciços e laminados cujo empi- 


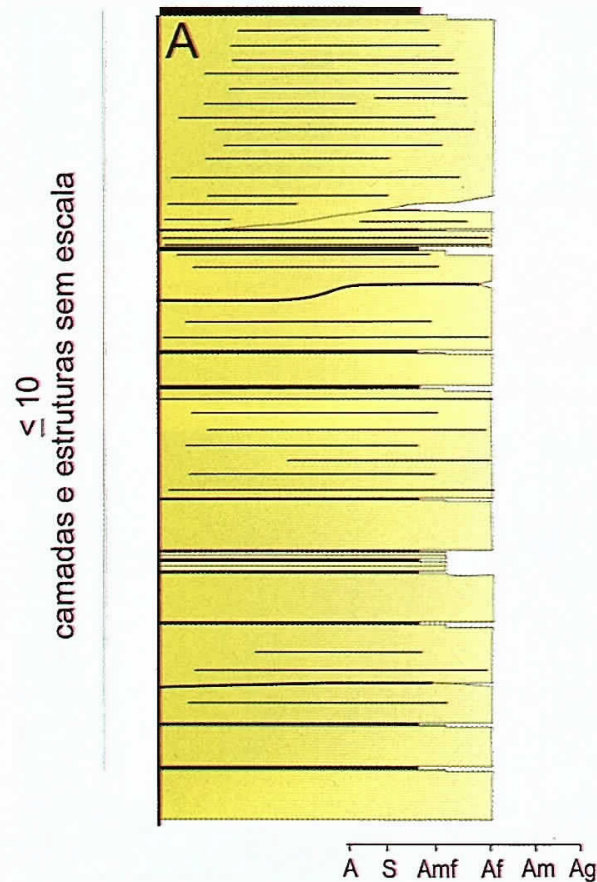

Lençol de areia proximal
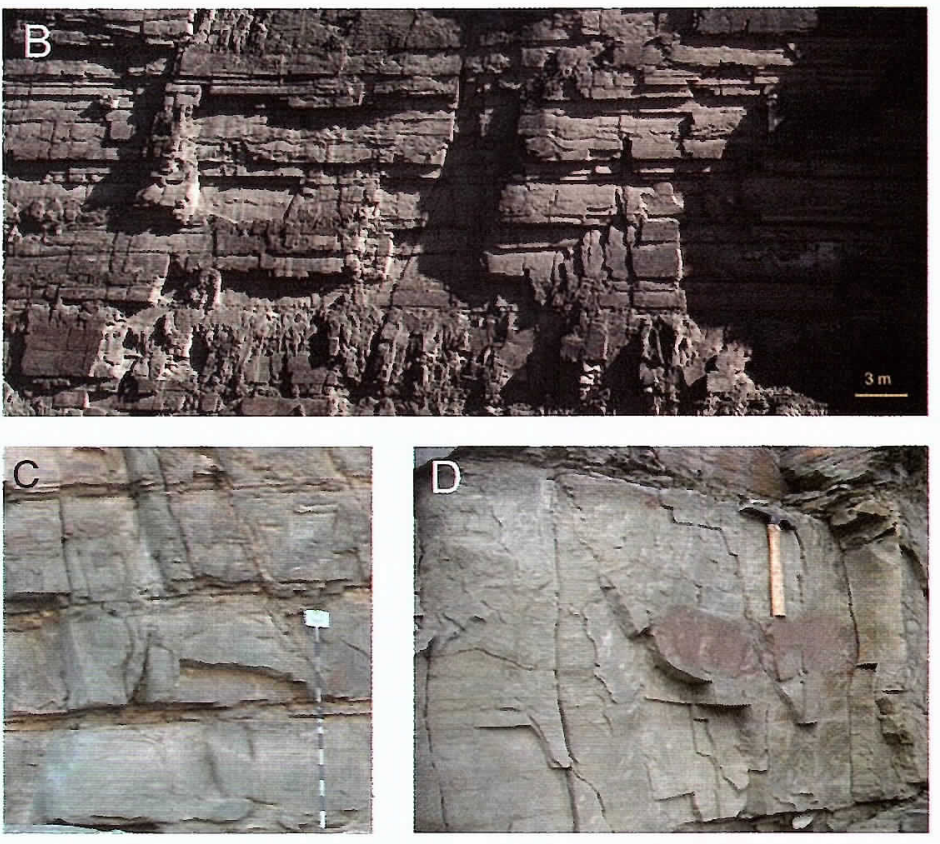

Figura 13 - Elemento arquitetural de Arenitos amalgamados interpretados como lençóis de areia proximal. (A) Esquema estratigráfico do elemento. As camadas e as estruturas não estão em escala. (B) Sucessão de camadas de arenitos amalgamados, de geometria tabular, às vezes apresentando formas levemente lenticulares. (C) Arenitos bipartidos, com uma porção basal composta de arenitos finos, sem estruturas, e uma porção superior com arenitos muito finos, com estruturas de tração. (D) Camada de arenito fino contendo estratificação plano-paralela. O contato entre as laminas é abrupto, às vezes contendo restos de fosseis vegetais. Martelo: $30 \mathrm{~cm}$.

lhamento atinge espessuras entre $10 \mathrm{~m}$ e $70 \mathrm{~m}$ (Figs. $13 \mathrm{~A}$ e B). Individualmente, as camadas são extensas e homogêneas, possuindo mais de $7 \mathrm{~km}$ de extensão lateral sem alterações de suas propriedades litológicas. Em escala de afloramento as camadas aparentam ser tabulares, devido a alta razão entre a largura e a espessura destes corpos. Corpos amalgamados são freqüentes, às vezes formando pacotes areníticos de até $4 \mathrm{~m}$.

Dois tipos principais de camadas constroem este elemento: i) arenitos bipartidos e ii) arenitos laminados.

Os arenitos bipartidos são formados por corpos individuais de espessura variando de $0,2 \mathrm{~m}$ a $>2 \mathrm{~m}$. Estas camadas são constituídas por duas porções distintas bem definidas: uma porção basal maciça e outra superior composta por laminações plano-paralelas (Fig. 13C). A porção basal é constituída por arenito fino, verde acinzentado. Os grãos são subangulosos a subarredendados e moderadamente selecionados. O nível superior é formado pela intercalação de arenito fino e muito fino, sendo caracterizado pela presença de estruturas sedimentares como laminações plano-paralelas, marcas onduladas de corrente e marcas de ondulas de corrente cavalgantes. Normalmente as estruturas estão dispostas, da base para o topo: laminação plano-paralela, marcas onduladas e de laminas planares de siltitos arenosos. A porção maciça é mais espessa que a porção laminada, geralmente atingindo $70 \%$ da espessura total da camada. Em algumas ocasiões o nível superior não ocorre, sendo o contato com a camada sobrejacente marcado por um nível delgado $(0,1$ a $1,0 \mathrm{~cm})$ de material pelítico arenoso sem estruturas aparentes. $\mathrm{Na}$ base, o contato pode ser marcado por feições erosivas, estruturas de sola como marcas de ranhuras (groove cast) $\mathrm{e}$ turboglifos (flute cast) aparecem ocasionalmente.

As camadas bipartidas são geradas a partir de um fluxos gravitacionais bipartidos, compostos por uma componente basal densa (fluxos de densidade concentrados) e uma componente turbulenta mais diluída (turbidity currents latu senso). A presença de marcas onduladas sobre as laminações plano-paralelas, observada muitas vezes nesta litofácies, é resultado de uma depleção gradual da energia do fluxo turbulento (waning flow) durante o processo deposicional.

As camadas de arenitos laminados são constituídas por arenitos finos a muito finos de coloração levemente esverdeada, com grãos sub-arredondados a sub-angulosos moderadamente selecionados. Uma das características principais destas camadas é a presença, às vezes abundante, de restos fósseis vegetais. Os arenitos laminados podem ser agrupados em corpos com laminação plano-paralela bem caracterizada e camadas com laminações difusas. No primeiro tipo, a laminação plano-paralela é caracterizada por sets de lâminas del- 
gadas, de espessuras variando entre 0,2 a $2 \mathrm{~cm}$, e contínuas, orientadas paralelamente ao acamamento (Fig. 13D). Comumente, as lâminas são definidas por súbitas alternâncias das características dos sedimentos, que passam de grãos de areia fina para uma associação de areia muito fina, silte, minerais placóides (como clorita, muscovita e biotita) e restos de fósseis vegetais. Esta associação de sedimentos se concentra em níveis muito delgados, geralmente $<1 \mathrm{~mm}$. Nestas camadas pode haver uma porção superior, geralmente pouco espessa $(>10 \mathrm{~cm})$, constituída por um material mais fino (areia muito fina e pelito arenoso) contendo laminas plano-paralela e marcas onduladas de corrente. O segundo tipo de camada é formado por arenito fino, com espessura variando entre $0,15 \mathrm{~m}$ e $1,0 \mathrm{~m}$, contendo como estrutura peculiar uma laminação plano-paralela pouco evidente. Esta laminação é marcada pela sutil alternância de granulação, entre areia fina e areia fina - muito fina. Marcas onduladas de corrente e lâminas paralelas de areia muito fina e pelito arenoso podem ocorrer no topo.

Os arenitos laminados são formados pela atuação de fluxos turbulentos (lato sensu). Laminação plano-paralela contendo mudanças bruscas de granulação é interpretada como sendo formada em condições de upper-stage plane beds (sensu Bridge \& Best, 1988; Paola et al., 1989).

Os arenitos laminados frequentemente apresentam estruturas convolutas. Laminações convolutas e estruturas almofadadas são as estruturas mais comuns. Embora estas ocorram obliterando estruturas pretéritas, muitas vezes marcas onduladas de corrente e laminação plano-paralela podem ser reconhecidas. As estruturas convolutas são estruturas de deformação em sedimentos não compactados, sua gênese é associada fenômenos de instabilidade que atuam durante ou após a deposição, que são resultado de um gradiente gravitacional instável decorrente da saturação e escape de água nos sedimentos.

A interestratificação das camadas areníticas maciças e laminadas configura este elemento. Os depósitos de lençol de areia proximal não apresentam nenhuma tendência vertical, caracterizando uma deposição sedimentar episódica. Seus depósitos ocorrem interdigitados com litossomas de lençol de areia distal ou bordejando o elemento de depósitos canalizados. Comumente ocorre um padrão de empilhamento tipo ciclos de compensação (Mutti \& Sonnino, 1981).

Os depósitos de lençóis de areia representam depósitos formados na terminação (desembocadura) de canais distributários durante o bypass do fluxo. A alta razão largura/espessura dos depósitos deste elemento indica que os litossomas foram gerados por fluxos desconfinados. As camadas de arenitos bipartidos tendem a ocorrer nas regiões mais próximas à desembocadura dos canais, enquanto que as camadas estratificadas ocupam porções mais distais.

ARENITOS DELGADOS - DEPÓSITOS DE LENÇOL DE AREIA DISTAL Este elemento arquitetural é constituído por camadas areníticas de granulometria fina (areia muito fina e silte) que são organizadas em pacotes com espessuras variando entre $2 \mathrm{~m}$ e $20 \mathrm{~m}$ (Figs.
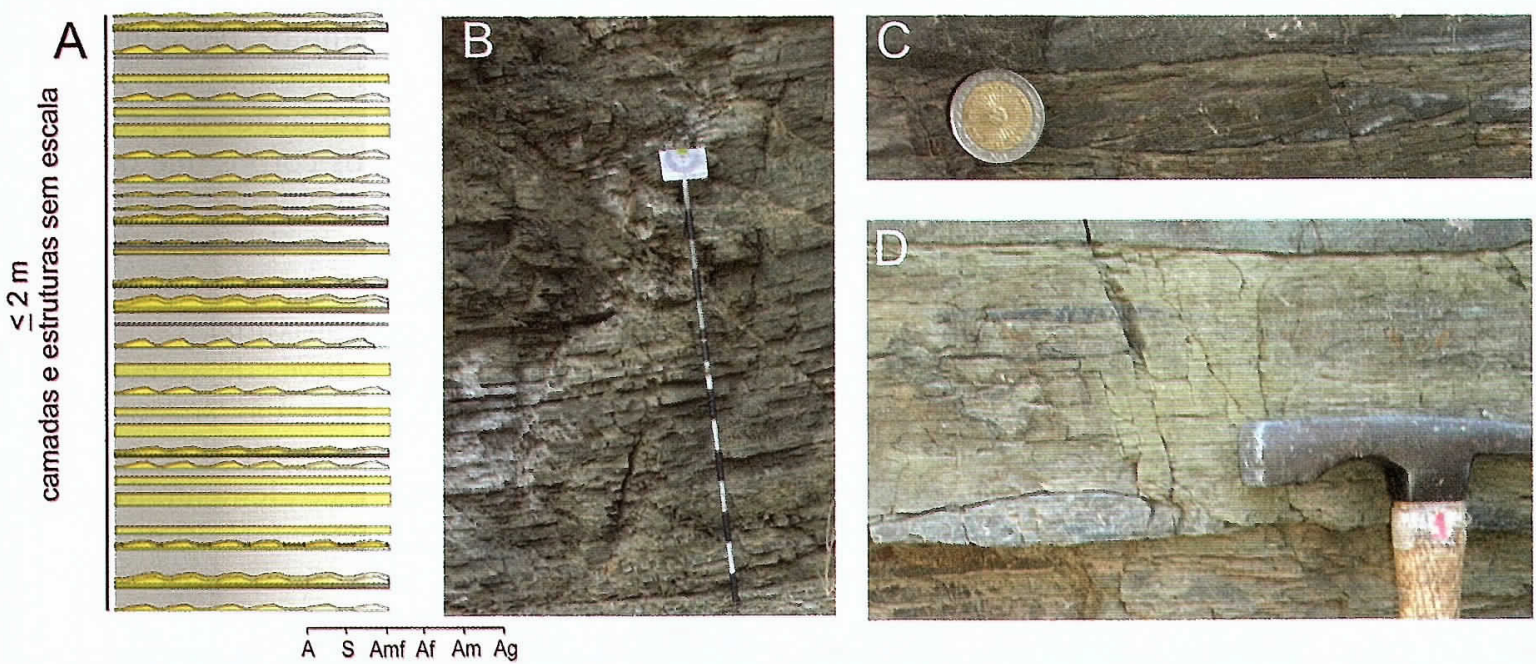

Figura 14 - Elemento arquitetural de Arenitos delgados interpretados como lençóis de areia distal. (A) Esquema estratigráfico do elemento. As camadas e as estruturas não estão em escala. (B) Sucessão de camadas de arenitos muito finos à arenitos siltosos. As camadas são pouco espessas, geralmente $<10 \mathrm{~cm}$. (C) Estrutura de marca ondulada de corrente isolada sobreposta por arenito siltoso. (D) Sets de camadas lenticulares de arenitos muito fino com estruturas de marcas onduladas de corrente isoladas sobrepostas por laminas de arenitos siltosos. Moeda 1,8 cm; Cabeça do martelo: $8 \mathrm{~cm}$. 
$14 \mathrm{~A} \mathrm{e} \mathrm{B)}$.

As camadas são sutis e formam corpos sedimentares extensos que podem ser traçados em afloramentos por mais de $500 \mathrm{~m}$. Geralmente as espessuras destas camadas variam entre 4 e $5 \mathrm{~cm}$, porém podem ultrapassar $10 \mathrm{~cm}$.

A baixa razão entre a espessura e a largura dos corpos fornecem a eles um aspecto tabular, porém as camadas apresentam um discreto adelgaçamento em direção às suas extremidades laterais formando lentes extensas.

As camadas possuem coloração cinza escura com tons esverdeados. Internamente, elas são formadas pela intercalação de arenito muito fino com material pelítico. A ótima seleção dos grãos e alta maturidade composicional são suas as principais características.

Dois tipos de camadas integram o elemento arquitetural. Um constituído por laminas plano-paralelas, que podem ser levemente sinuosas, e o outro caracterizado por corpos areníticos lenticulares formados por marcas de corrente e marcas cavalgantes sobrepostos por laminas plano-paralela de arenito muito fino e pelito arenoso. Marcas de corrente isoladas (starved ripples), geradas por um suprimento insuficiente de sedimentos, também estão presentes e possuem entre 0,5 e $2,0 \mathrm{~cm}$ de espessura (Figs. 14C e D). No topo das camadas pode haver uma gradação ascendente entre arenito siltoso e siltito. Às vezes, tal gradação é indistinta caracterizando contatos bruscos entre as camadas. Estruturas convolutas ocorrem em algumas camadas.

Os corpos sedimentares deste elemento, bem como suas estruturas sedimentares internas, 'são gerados pela atuação de fluxos gravitacionais turbulentos de baixa concentração (correntes turbidíticas sensu stricto). $\mathrm{O}$ aspecto tabular das camadas denota fluxos em condições não confinadas.

Este elemento pode ser atribuído como depósitos de lençóis de areia distais, gerados nas regiões frontais dos lençóis de areia (lobos). Embora extensos, os litossomas deste elemento possuem características internas e externas homogêneas, conservando propriedades faciológicas e petrofísicas, como permeabilidade e porosidade.

Os litossomas deste elemento interdigitam-se com depósitos do elemento de lençol de areia proximal.

Arquitetura do Sistema Deposicional de Água Profunda Rico em Areia As principais características dos sistemas de rampa submarina rica em areia são: i) ausência quase completa de sedimentos pelíticos, ii) pouca variedade de elementos arquiteturais e iii) organização simples entre os elementos arquiteturais.

Três elementos arquiteturais foram reconhecidos, sendo eles formados por: Depósitos de canais distributários, Depósitos de lençol de areia proximal e Depósitos de lençol de areia distal. Estes elementos caracterizam a porção medial-distal do sistema de rampa submarina profunda, na transição entre os canais distributários e as porções distais dos lençóis de areia (Fig.

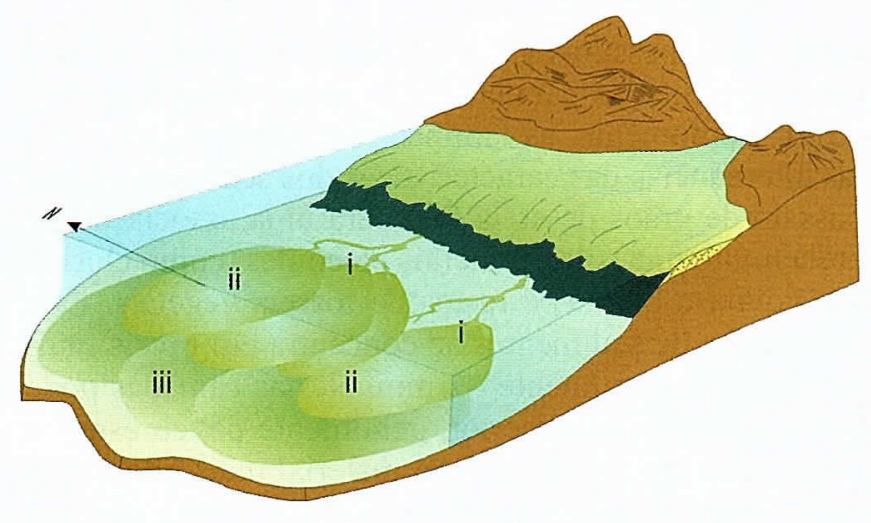

Figura 15 - Esquema da distribuição dos elementos arquiteturais e hipotética reconstrução do sistema deposicional da Formação Punta Negra. i) Depósitos de preenchimento de canal; ii) Depósitos de lençol de areia proximal; iii) e Depósitos de lençol de areia distal.

15).

As análises de paleocorrentes, realizadas nos três elementos arquiteturais, mostraram uma direção preferencial de evolução do paleofluxo de leste para oeste. Os indicadores utilizados foram estruturas de marcas onduladas de correntes e marcas de sola. Embora os dados apresentem uma direção preferencial, há uma pequena dispersão dos dados entre N248-329 (Fig. 16).

Os Depósitos de canais constituem aproximadamente $20 \%$ das sucessões estudadas. Este elemento constitui a porção mais proximal do sistema estudado, sendo formado por espessas camadas de arenito médiofino. Apesar deste fato, ele não constitui corpos reservatórios contíguos muito amplos, possuindo espessuras até $40 \mathrm{~m}$ e larguras que não ultrapassam $300 \mathrm{~m}$.

As significativas variações de propriedades litológicas e geométricas dos corpos que ocorrem a distâncias laterais relativamente curtas são características importantes nos reservatórios de canais. Os Depósitos de canais são circundados por corpo areníticos de Depósitos de lençóis de areia proximal.

Os Depósitos de lençóis de areia proximal formam aproximadamente $44 \%$ das seções estudadas e são frequentemente interestratificados com Depósitos de lençóis de areia distal. Este elemento forma extensos ( $>7 \mathrm{~km}$ de largura) e espessos (até $70 \mathrm{~m}$ de espessura) reservatórios. As litofácies são homogêneas, não mostrando grandes mudanças petrofísicas dentro de uma mesma camada. As pequenas variações petrofísicas que ocorrem nestas litofácies se devem principalmente a presença de níveis areníticos siltosos e pelito arenoso na porção superior de algumas camadas. Estes níveis que podem proporcionar variações verticais de permeabilidade e porosidade.

Apesar de conterem quantidades muito baixas de sedimentos pelíticos, os Depósitos de lençóis de areia distais representam os sedimentos mais finos do 


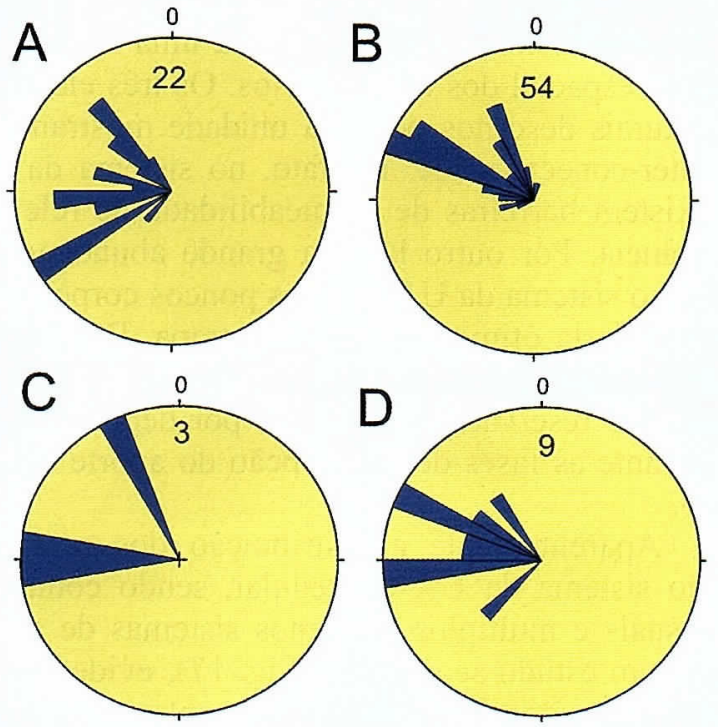

Figura 16 - Dados de paleocorrentes dos elementos parquiteturais da Formação Punta Negra. A posição dos afloramentos é indicada na Fig. 11. (A) Afloramento 1, direção de foresets de marcas onduladas de corrente e de marcas de sola dos elementos de Depósito de lençóis de areia proximal e Depósito de lençóis de areia distal. (B) Afloramento 2, direção de foresets de marcas onduladas de corrente e de marcas de sola dos elementos de Depósito de lençóis de areia proximal e Depósito de lençóis de areia distal. (C) Afloramento 3, direção de foresets de marcas onduladas de corrente de Depósito de lençóis de areia distal. (D) Afloramento 4 direção de foresets de marcas onduladas de corrente e de marcas de sola dos elementos de Depósito de canais e Depósitos de lençóis de areia proximal.

sistema profundo da FPN. Estes formam corpos extensos e pouco espessos raramente ultrapassando $2 \mathrm{~m}$ de espessura. Entre seus principais atributos destacam-se a homogeneidade das litofácies e a excelente seleção dos grãos. Os corpos gerados nas frentes dos lençóis de areia possuem uma permeabilidade vertical menor devido à presença de sedimentos na fração silte entre as camadas de areia.

DIFERENÇAS DOS DOIS SISTEMAS DE RAMPA NA GERAÇÃO DE RESERVATÓRIOS Os elementos arquiteturais descritos nos dois sistemas deposicionais mostram alguns pontos em comum e muitas divergências. Consequentemente, forma, dimensão, conectividade e capacidade de formar complexos de trapas em sistema petrolíferos são marcadamente diferentes.

A maior similaridade entre os dois sistemas consiste em ser atribuídos a sistemas de rampa, pois ambos são caracterizados por múltiplos distribuidores de sedimentos ao longo de uma margem.
As numerosas diferenças são assim resumidas: i) dimensões da bacia; ii) percentual de distribuição de pelito; iii) gama de difusão das classes granulométricas e tipos de fluxos gravitacionais; iv) tipo dos elementos arquiteturais e caracterização dos reservatórios; v) distribuição espacial dos elementos arquiteturais e conectividade dos reservatórios.

A discrepância na magnitude dos dois sistemas deposicionais se constitui numa das diferenças mais marcantes. Os depósitos de água profunda da UA extendem-se só por uma limitada porção da Bacia do Itajaí, que cobre uma área inferior a $100 \mathrm{~km}^{2}$. Por outro lado, a distribuição areal em afloramento da FPN é maior que $1.000 \mathrm{~km}^{2}$. Sistemas deposicionais com escalas tão díspares implicam em diferenças no tamanho dos sistemas de alimentação, no espaço disponível para sedimentação, no volume de sedimento envolvido e, consequentemente, refletindo nas dimensões dos reservatórios neles contidos.

Outra diferença importante entre os dois modelos é a distribuição de pelito: no modelo da UA a percentual de difusão dos pelitos é superior a $80 \%$, quando no modelo da FPN não supera $10 \%$. A presença de argila influencia velocidade e inércia dos fluxos gravitacionais, permitindo a construção de sistema deposicionais alongados na direção das paleocorrentes. A relação comprimento:largura do modelo derivado da UA é maior que no modelo derivado da FPN. Além disso, a maior difusão de pelito determina uma menor distribuição, em percentual, dos reservatórios e gera barreiras de permeabilidade internas e externas dos corpos reservatórios.

O sistema da UA mostra uma maior distribuição da gama das classes granulométricas. Este aspecto é associado a uma maior variedade dos mecanismos deposicionais. No sistema da UA foram descritos mecanismos gravitacionais de alta até muito baixa densidade: de fluxos por escorregamento (slumping) ou de flow-slide até correntes de turbidez de alta diluição. Ao contrário, no sistema da FPN prevalecem só dois tipos de fluxos: fluxos de densidade concentrados e correntes de turbidez com variado grau de diluição. Os tipos de fluxos são associados com as classes granulométricas depositadas e com o grau de seleção dos sedimentos, dessa forma, o sistema da FPN mostra uma maior homogeneidade de características granulométricas e um maior grau de seleção.

Números e caracteres dos elementos arquiteturais descritos nos dois sistemas são substancialmente diferentes. O modelo derivado da UA mostra cinco elementos, dos quais três são potenciais reservatórios. Os Arenitos amalgamados, que correspondem à deposição de lençóis de areia proximais, são os melhores reservatórios sendo constituídos por arenito médio-fino, com boa seleção, camadas com espessura média de $1,5 \mathrm{~m}$, amalgamadas, que formam corpos espessos até 20$200 \mathrm{~m}$, largos até $8 \mathrm{~km}$. Arenitos com sutis camadas de pelitos, interpretados como lençóis de areia distal, constituem o segundo tipo de reservatórios em ordem de potencialidade. Estes são formados por pacotes de 
arenitos amalgamados, espessos até $10 \mathrm{~m}$ e largos até $1 \mathrm{~km}$, sendo, entretanto, caracterizados por freqüentes intercalações de Pelitos e sutis camadas de arenitos. A parte inferior do elemento Conglomerados, arenitos e interestratificações de arenitos e pelitos, interpretada como preenchimento de canal, é o terceiro tipo de reservatórios. As dimensões destes reservatórios são inferiores aos anteriores, os depósitos são mais grossos e menos selecionados, mostrando parâmetros petrofísicos de qualidade inferior.

Os três elementos arquiteturais individualizados no sistema da FPN (Arenitos Canalizados, Arenitos amalgamados e Arenitos Delgados) constituem três corpos reservatórios de ótima qualidade. O elemento Arenitos amalgamados, constituído por deposição de lençóis de areia proximais constitui o principal alvo da exploração, sendo constituído por camadas mais espessas de $1 \mathrm{~m}$, amalgamadas, que formam litossomas até $70 \mathrm{~m}$ espessos e mais de $7 \mathrm{~km}$ largos. O elemento Arenitos delgados, produzido por deposição de lençóis de areia distais, constitui reservatórios com qualidades melhores de que os análogos da UA. O terceiro elemento arquitetural (Arenitos canalizados) é constituído por corpos que preenchem estruturas canalizadas compostas. Este elemento possui características de ótimo reservatório, devido a maior granulometria e alta seleção, porém as dimensões destes elementos (até $40 \mathrm{~m}$ espessos e até $300 \mathrm{~m}$ largo) são inferiores aos outros dois elementos.
O modelo da FPN apresenta uma melhor distribuição espacial dos reservatórios. Os três elementos arquiteturais descritos por esta unidade mostram uma alta inter-conectividade. De fato, no sistema da FPN não existem barreiras de permeabilidade de relevante importância. Por outro lado, a grande abundância de pelitos no sistema da UA isola os poucos corpos reservatórios e cria ótimos sistemas de trapa. Barreiras de permeabilidade e porosidade observam-se também no interno dos reservatórios, geradas por deposição pelítica durante as fases de interrupção do aporte clástico grosso.

Aparentemente a distribuição dos reservatórios no sistema da UA é irregular, sendo controlada por casuais e múltiplos pequenos sistemas de aporte. Porém, um estudo seqüencial (Fig. 17), evidencia que a distribuição dos reservatórios concentra-se em cinco intervalos estratigráficos. Ao longo destes intervalos a distribuição, concentração e conectividade dos reservatórios são muito mais altas, podendo assim constituir um importante alvo da indústria de extração de hidrocarbonetos.

Concluindo, o sistema da FPN demonstra ser um sistema muito menos complexo do sistema da UA em relação à qualidade, quantidade e conectividade dos reservatórios. Todavia, no sistema da FPN a carência de depósitos pelíticos determina a quase completa ausência de barreira de permeabilidade e, consequentemente, a ausência de um complexo de rochas selantes.

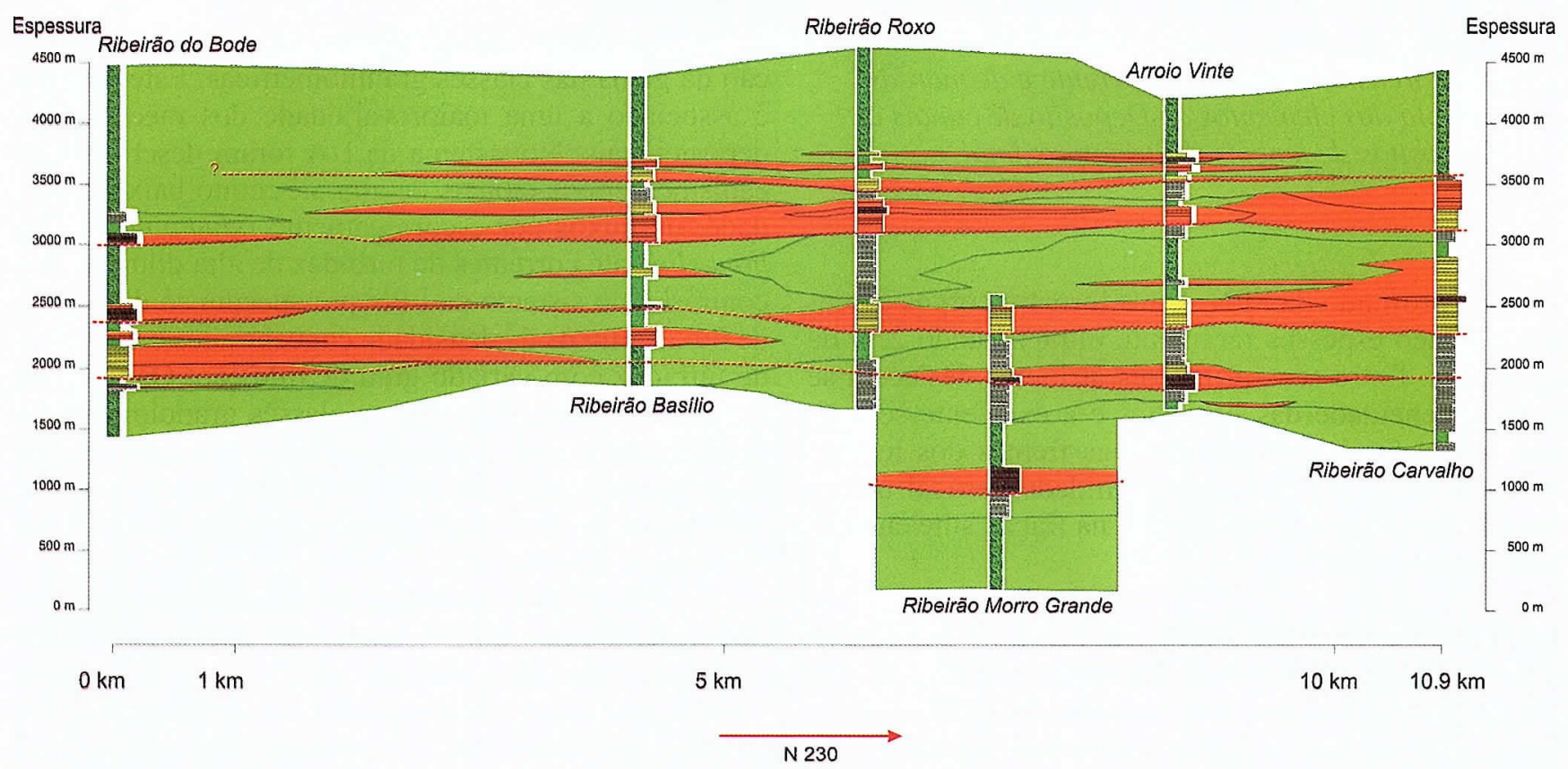

LEGENDA

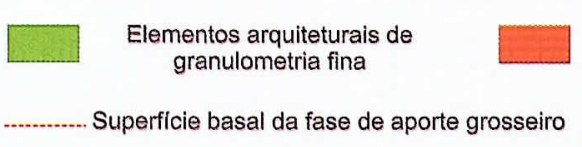

Elementos arquiteturais de

granulometria grosseira

Figure 17 - Diagrama de cerca da UA filtrado para evidenciar os corpos mais grossos, potenciais reservatórios, dos elementos mais finos, potenciais rochas selantes. 
Deste ponto de vista, o sistema de Apiúna resulta ser mais completo sendo que rochas selantes são geradas no âmbito no mesmo sistema deposicional.

CONCLUSÕES Considerando-se que os sistemas deposicionais de água profunda constituem um objeto de importância estratégica pela indústria petrolífera, foram estudados os afloramentos de dois sistemas de rampa submarina (sensu Reading \& Richards, 1994) com a finalidade de determinar as características dos potenciais reservatórios. Foi analisado um sistema de rampa rico em pelito, representado pela Unidade de Apiúna (UA), pré-Cambriano do Estado de Santa Catarina, e um sistema de rampa rico em areia, representado pela Formação de Punta Negra (FPN), Devoniano da PréCordilheira Argentina.

O estudo de análogos foi feito mediante o uso de elementos arquiteturais, porque estes permitem o melhor reconhecimento de corpos reservatórios. Cinco elementos arquiteturais foram identificados na UA. Dois deles (Pelitos laminados e depósitos de escorregamento (slumping), Pelitos e sutis camadas de arenitos), que respectivamente correspondem a um sopé lamoso (muddy rise) e a depósitos de overbank ou inter-canal, constituem um sistema de rochas selantes. Os elementos arquiteturais identificados com os reservatórios são: Arenitos amalgamados, Arenitos com sutis camadas de pelitos, Conglomerados, arenitos e interestratificações de arenitos e pelitos. Estes, respectivamente, correspondem a depósitos de lençóis de areia proximais, lençóis de areia distais e canais e diques marginais. Este sistema mostra uma baixa distribuição volumétrica de reservatórios $(<20 \%)$, que comumente apresentam barreiras internas.
O sistema deposicional da FPN é caracterizado por mais de $90 \%$ por areia e, em geral, com alta seleção. Os três elementos arquiteturais reconhecidos formam ótimos reservatórios: Arenitos canalizados (depósitos preenchimento de canais), Arenitos amalgamados (depósitos de lençol de areia proximal) e Arenitos delgados (depósitos de lençol de areia distal). As melhores condições de reservatório localizam-se nos depósitos de lençóis proximais.

Tendo em consideração as propriedades petrofísicas, dimensões e conectividade dos reservatórios o sistema de rampa rico em areia da FPN constitui um sistema deposicional mais atraente pela exploração de hidrocarbonetos. O sistema de rampa rico em pelito, representado pelo sistema deposicional da UA, forma um alvo muito menos atraente pela exploração.

Todavia, o sistema de rampa rica em pelito possui, diferentemente do outro, a capacidade de gerar sistemas de trapas e em determinados intervalos estratigráficos, representados por concentrações de aporte clástico, apresenta uma alta concentração de reservatórios, naturalmente selados pela deposição sucessiva de pelito. Desta forma, se outras condições geológicas não são geradas, sistemas de rampa rica em areia podem possuir baixa capacidade de retenção de hidrocarbonetos.

Agradecimentos Este trabalho deve-se ao apoio financeiro da Fapesp (projetos 02/115246, 06/000220) e PRH-ANP15.Agradecemos Saul Suslick pela oportunidade de contribuir com a nossa pesquisa a este volume e o assessor (Saulo F. Santos) pelos comentários úteis para melhorar o texto e para nos deixar refletir.

\section{Referências}

Ambrose W.A., Tyler N., Parsley M.J. 1991. Facies heterogeneity, pay continuity, and infill potential in barrier-island, fluvial, and submarine-fan reservoirs: example from the Texas Gulf Coast and Midland Basin. In: Miall A.D. \& Tyler N. (eds.) The three-dimensional facies architecture of terrigenous clastic sediments and its implications for hydrocarbon discovery and recovery. SEPM, Concepts in Sedimentology and Paleontology 3, p. 13-21.

Astini B.A. 1990. Formación Punta Negra: Um abanico submarino o um complejo deltáico de plataforma? In: Reunión Argentina de Sedimentologia, 3, atas, p.13-18.

Basilici G. \& Martins J. L. 2004. Architectural reinterpretation and acoustic facies of the lower portion of the Apiúna Unit (Cambrian deep-water depositional system, Santa Satarina State, Brazil). Rev. Bras. Geoc., 34(3):335-346.

Basilici G. 2006. Depositional mechanisms and architecture in an pre-early Cambrian deep-water ramp (Apiúna Unit, South Brazil). Sedimentary Geology, 187:183-204.

Bouma A.H. 2000. Coarse-grained and fine-grained turbidite systems as end member models: applicability and dangers. Marine and Petroleum Geology, 17:137-143.

Bouma A.H. 2004. Key controls on the characteristics of turbidite systems, In: Lomas S. A. and Philippe J. (eds.) Confined turbidite systems: Geological Society (London) Special Publication, 222, p. 9-22.

Bridge S. \& Best J.L. 1988. Flow, sediment transport and bedform dynamics over the transition from dunes to upper-stage plane beds: implications for the formation of planar laminae. Sedimentology, 35:753-763.

Bustos U. 1996. Modelo sedimentário alternativo para el Devónico de la Precordillera central sanjuanina: Formación Punta Negra. Revista de la Asociación Geológica Argentina, 3:17-30.

Gonzales Bonorino G. \& Middleton G.V. 1976. A Devonian submarine fan in western Argentina. Journal of sedimentary Petrology, 46(1):56-69.

Bustos U. \& Astini R. A. 1997. Formación Punta Negra: análisis secuencial y evolución de la Cuenca Devónica Precordillerana. Revista de la Asociación Geológica Argentina, 4:97-109.

Gonzales Bonorino G. \& Middleton G.V. 1976. A Devonian submarine fan in western Argentina. Journal of sedimentary Petrology, 46(1):56-69.

Kirschner R.H. \& Bouma A.H. 2000. Characteristics of a 
distributary channel-levee-overbank system, Tanqua Karoo. In: Bouma A.H., \& Stone C.G. (eds.) Fine-Grained Turbidite Systems. AAPG, Memoir 72. SEPM, Special Publication 68, p. 279-289.

Kneller B.C. 1995. Beyond the turbidite paradigm: physical models for deposition of turbidites and their implications for reservoir prediction. In: Hartley A.J. \& Prosser D.J. (eds.) Characterization of Deep Marine Clastic Systems. Geol. Soc. London, Spec. Publ., 94, p.31-49.

Krebs J.A.S., Caldasso da S.A.L., Lopes da C.R., Camozzato E. 1988. Interpretação preliminar da seqüência deposicional da Bacia do Grupo Iatajái na área da Folha Botiverá - SC. In: Congresso Brasileiro de Geologia, 35, Belém, Pará, Atas, v.2, p. 592-605.

Lowe D.R. 1982. Sediment gravity flows: II. Depositional models with special reference to the deposits of highdensity turbidity currents. Journal of sedimentary Petrology, 52:279-297.

Mattern F. 2005. Ancient sand-rich submarine fans: depositional systems, models, identification, and analysis. Earth-Science Reviews, 70:167-202.

Mulder T. \& Alexander J. 2001. The physical character of subaqueous sedimentary density flows and their deposits. Sedimentology, 48:269-299.

Mutti E. 1977. Distinctive thin-bedded turbidite facies and related depositional environments in the Eocene Hecho Group (South-central Pyrenees, Spain). Sedimentology, 24:107-131.

Mutti E. \& Sonnino M. 1981. Compensation cycles: a diagnostic feature of turbidite sandstone lobes. In: Valloni R., Colella A., Sonnino M., Mutti E., Ori G.G. (eds.) International Association of Sedimentologists, $2^{\text {nd }}$, European Regional Meeting, Bologna, Italy, Abstracts, p. 120-123.

Mutti E. \& Normark W.R. 1991. An integrated approach to the study of turbidite systems, In: Weimer P. \& Link M.H. (eds.) Seismic facies and sedimentary processes of submarine fans and turbidite systems. New York, Springer-Verlag, p.75-106.

Paola C., Wiele S.M., Reinhart M.A. 1989. Upper-regime parallel lamination as the result of turbulent sediment transport and low-amplitude bed forms. Sedimentology, 36:47-59.

Pickering K.T., Clark J.D., Smith R.D.A., Hiscott R.N., Ricci Lucchi F., Kenyon, N.H. 1995. Architectural elements analysis of turbidite systems, and selected topical problems for sand-prone deep-water systems. In: Pickering K.T., Hiscott R.N., Kenyon N. H., Ricci Lucchi F., Smith R.D.A. (eds.) Atlas of deep Water Environments. Chapman \& Hall, London, p. 1-11.

Posamentier H.W. \& Walker R.G. 2006. Deep-water turbidites and submarine fans. In: Posamentier H.W. \& Walker R.G. (eds.) Facies model revisited. SEPM, Spec. Publ., 84, p. 397-520.
Reading H.G. \& Richards M.T. 1994. Turbidite systems in deep water basin margins classified by grain-size and feeder system. AAPG Bull., 78:792-822.

Richards M.T. 1996. Deep-marine clastic systems. In: D. Emery \& K.J. Myers (eds.) Sequence stratigraphy, Blackwell Science, p.:178-210.

Rigon F.C. 1993. Petrologia e proveniência dos depósitos turbidíticos da Bacia de Itajai, Estado de Santa Catarina, Brasil. Dissertação de Mestrado, Instituto de Geociências, Universidade de Ouro Preto, 170 p.

Rostirolla S.P., Ahrendt A., Soares P.C., Carmignani L. 1999. Basin analysis and mineral endowment of the Proterozoic Itajaí Basin, south-east Brazil. Basin Research, 11:127-142.

Shanmugam G. 2000. 50 years of the turbidite paradigm (1950s-1990s): Deep-water Processes and Facies Models: a critical perspective. Marine and Petroleum Geology, 17:285-342.

Slatt R.M. 2000. Why Outcrop Characterization of Turbidite System. In: Bouma A.H., \& Stone C.G. (eds.) FineGrained Turbidite Systems. AAPG, Memoir 72. SEPM, Special Publication 68, p.181-185.

Stanley D.J. \& Maldonado A. 1981. Depositional models for fine-grained sediments in the western Hellenic Trench, eastern Mediterranean. Sedimentology, 28:273-290.

Stow D.A.V. \& Mayall M. 2000. Deep-water sedimentary systems: New models for the $21^{\circ}$ Century. Marine and Petroleum Geology, 17:125-135.

Stow D.A.V. \& Johansson M. 2000. Deep-water massive sands: nature, origin and hydrocarbon implications. $\mathrm{Ma}$ rine and Petroleum Geology, 17:145-174.

Surlick F. 1987. Slope and Deep Shelf Gully San stones, Upper Jurassic, East Greenland. AAPG Bulletin, 71:464475.

Tinterri R., Drago M., Consonni A., Davioli G., Mutti E., 2003. Modelling subaqueous bipartide sediment gravity flows on the basis of outcrop constraints: first results. Marine and Pretoleum Geology, 20: 911-933.

Tyler N. \& Finley R.J. 1991. Architectural control on the recovery of hydrocarbon from sandstone reservoirs. In: A.D. Miall \& N. Tyler (eds.) The three dimensional facies architecture of terrigenous clastic sediments and its implications for hydrocarbon discovery and recovery. SEPM, Concepts in Sedimentology and Paleontology, 3, p.1-5.

Tyler N. 1988. New oil from old field. Geotimes, 33(7):810.

Walker R.G. 1975. Nested submarine channels at San Clemente, California. Geological Society of America Bulletin, 86:915-924.

Manuscrito BR 12

Submetido em 26 de dezembro de 2007 Aceito em 10 de março de 2008 